\title{
Global DNA Methylation Profiles of Buffalo (Bubalus Bubalis) Preimplantation Embryos Produced by Handmade Cloning and in Vitro Fertilization
}

Shivani Malpotra ( $\square$ malpotras@gmail.com )

ICAR-National Dairy Research Institute (Deemed University)

Pallavi Goel

ICAR-National Dairy Research Institute (Deemed University)

Songyukta Shyam

ICAR-National Dairy Research Institute (Deemed University)

Manoj Kumar Singh

ICAR-National Dairy Research Institute (Deemed University)

Prabhat Palta

ICAR-National Dairy Research Institute (Deemed University)

\section{Research Article}

Keywords: Somatic cell nuclear transfer, in vitro fertilization, DNA methylation, next-generation sequencing, buffalo

Posted Date: June 1st, 2021

DOI: https://doi.org/10.21203/rs.3.rs-550977/v1

License: (c) (i) This work is licensed under a Creative Commons Attribution 4.0 International License. Read Full License

Version of Record: A version of this preprint was published at Scientific Reports on March 25th, 2022. See the published version at https://doi.org/10.1038/s41598-022-09207-8. 


\section{Abstract}

Somatic cell nuclear transfer technique (SCNT) has proved to be an outstanding method of multiplication of elite animals but accompanied with low efficiency and live birth rate of cloned animals. Epigenetic alterations of DNA has been one of the culprits behind this issue. Cloned embryos are found to deviate slightly from regular pattern of demethylation and re-methylation at the time of nuclear reprogramming and embryonic development when compared with embryos produced by in vitro fertilization (IVF). Thus, the present study was aimed at evaluating global DNA methylation profiles of cloned embryos at 2cell, 8-cell and blastocyst stages and compare it with corresponding stages of embryos produced by IVF by using MeDIP-Sequencing on Illumina-based platform. We found out that cloned embryos exhibited significantly different DNA methylation pattern as compared to IVF embryos with respect to distribution of differentially methylated regions in different components of genome, $\mathrm{CpG}$ islands distribution and methylation status, gene ontological profiles and pathways affected throughout the developmental stages. The data generated from MeDIP-Seq was validated at blastocyst stage cloned and IVF embryos by bisulfite-sequencing PCR on five randomly selected gene regions.

\section{Introduction}

The field of embryology gained emphasis in scientific research with the success of somatic cell nuclear transfer (SCNT) technique. With the birth of cloned sheep "Dolly" in 1997 by SCNT ${ }^{1}$, researchers became more interested in exploring the molecular events involved in reprogramming of reconstructed embryos throughout the developmental stages. SCNT technique is based on converting a differentiated somatic cell to the totipotent state upon reprogramming of epigenetic marks by the factors present in the cytoplasm of the enucleated oocyte. Till date, more than 20 mammalian species have been cloned, using different type of somatic cells ${ }^{2}$, for multiple purposes including agriculture, biomedical industry, disease modelling, therapeutic cloning, bio-pharming, conservation and restoration of endangered species and xenotransplantation demonstrating the usefulness of this procedure 3 .

In the context of farm animals, perhaps the most important application of SCNT is the fast multiplication of elite animals at a rate much faster than conventional breeding ${ }^{4}$. Despite successful cloning in several farm animal species, SCNT has not been implemented on a large scale primarily due to the very low live birth rate obtained with cloned embryos ${ }^{2,5-8}$. In comparison with the live birth rate obtained with bovine embryos produced by in vitro fertilization (IVF) which is over $40 \%{ }^{9}$, the live birth rate obtained with cloned embryos is very low. In cattle, it is only $9 \%{ }^{5,10}$ to $5-20 \%{ }^{2,11}$ whereas, across species, the live birth rate obtained with cloned embryos is only $1-6 \% 6,11,12$. In buffalo too, the live birth rate is $<2 \%{ }^{13,14}$. This is due to a multitude of reasons such as low conception rate, high abortion rates, prolonged gestation, high incidence of abnormalities such as large offspring syndrome, severe placental deficiency, respiratory problems, short life span and perinatal death ${ }^{15-18}$.

SCNT is a complex technique with several factors which can influence its outcome such as the quality of recipient oocyte in terms of its cytoplasmic volume and factors necessary for reprogramming donor nucleus $19,20,21$, origin, quality and plasticity of nucleus of donor somatic cell 22,23 and technical skill-based and biological variations in different steps of cloning procedure ${ }^{24}$. Although the exact reasons behind the problems associated with cloning through SCNT are not fully understood, incomplete nuclear reprogramming is considered to be the principal reason responsible for the abnormalities in cloned embryos. Nuclear reprogramming is the process of reversing a differentiated somatic nucleus to the totipotent state of the embryo after nuclear transfer ${ }^{25}$. This involves changes in the expression profile of 10,000 to 12,000 genes which drive the embryonic and fetal development ${ }^{26}$. During nuclear reprogramming, the epigenetic marks specific to the differentiated somatic cell must be fully erased, and those associated with the totipotent stage of the embryo must be reestablished. The epigenetic reprogramming after SCNT has been often found to be abnormal or aberrant ${ }^{25}$. Therefore, epigenetics plays a crucial role in determining the cloning efficiency and the fate of cloned offspring born.

Major epigenetic processes involve DNA methylation, chromatin remodelling, histone modifications and regulation of gene expression by noncoding RNAs ${ }^{27}$, 28, 29. DNA methylation and histone tail modifications play important roles during nuclear reprogramming as they alter chromatin condensation and DNA accessibility to regulate key cellular processes such as DNA replication and repair, gene transcription, and cell cycle progression etc., alterations which lead to developmental failures of cloned embryos ${ }^{30,31}$.

DNA methylation occurs predominantly at $\mathrm{CpG}$ dinucleotides and is involved in several key genome functions such as imprinting, X-chromosome inactivation, genome stability, silencing of retrotransposons and inactivation of cancer-related genes ${ }^{32,33}$. Basically, DNA methylation suppresses gene expression by recruiting methyl- CpG-binding proteins such as MECP2 (methyl-CpG-binding protein 2), MBD1 (methyl-CpG-binding domain protein 1), MBD2, and MBD3, as well as associated histone deacetylases, co-repressor proteins and chromatin remodelling machineries at the promoter regions of specific genes ${ }^{34}$. DNA demethylation holds an important place in reprogramming of SCNT embryos because it is the initial step that occurs during reprogramming. DNA methylation is necessary for transcription of octamer-binding transcription factor 4 (OCT4) which is critical factor for pluripotency thus, certifies initiation and maintenance of early embryonic development after successful cloning ${ }^{35,36}$. Therefore, aberrant DNA methylation may cause abnormal gene expression during initial stages of development, ultimately leading to embryo/fetal developmental failure $25,37-40$.

Several studies have been made to investigate DNA methylation profile in SCNT embryos and compare it with their IVF counterparts. In earlier studies, it was done by using techniques such as immunofluorescence staining, Western blotting etc. However, this could generate very limited information. Later, comprehensive genome-wide methylome was studied by applying several Next Generation Sequencing (NGS) strategies such as Whole Genome Bisulfite Sequencing (WGBS) and Reduced Representation Bisulfite Sequencing (RRBS) ${ }^{41}$. WGBS has been used to produce methylation profiles of (SP-A) gene promotor and a satellite DNA (Rsat IIE) in cloned and in vitro fertilized embryos in rabbit ${ }^{42}$, sperm cells of cloned mouse ${ }^{43}$ and sperm, immature oocytes, in vivo and in vitro matured oocytes and in vivo derived embryos at 2-, 4-, 8-, and 16-cell stages in bovine ${ }^{44}$. Chan et al. (2012) ${ }^{41}$ generated genome-wide DNA methylation profile from donor fibroblasts and SCNT mouse embryos with single base-pair resolution using RRBS method. Similarly, genome-wide DNA 
methylation profiles of bovine sperm, in-vivo developed oocyte and preimplantation embryos was established by using RRBS ${ }^{45}$. Although, WGBS and RRBS can generate single base-resolution DNA methylome but these techniques cause substantial DNA degradation and the results depend on conversion efficiency. Additionally, special enzymes are required for library preparation making these techniques extremely costly. These shortcomings can be overcome to a large extent by using Methylated DNA Immunoprecipitation Sequencing (MeDIP-Seq) technique. Although, this technique can generate only relative enrichment of specific regions across the genome, its low cost and minimum reagent requirement makes it a better choice for studying DNA methylome. In addition, it only requires a good quality of genomic DNA and a specific antibody.

To our information, there is only one report available on genome-wide DNA methylation profile of SCNT embryos in farm animals ${ }^{46}$. However, there is no report till date on the global DNA methylation profiling examined using a high throughput NGS technique in embryos produced by SCNT and IVF in any species. Thus, in the present study, we carried out genome-wide DNA methylation profiling in buffalo embryos produced by handmade cloning (HMC) and invitro fertilization (IVF) by using methylated DNA immunoprecipitation combined with high-throughput sequencing (MeDIP-Seq). To our knowledge, this is the first report on global DNA methylation pattern of cloned embryos relative to IVF counterparts in buffalo.

\section{Methods}

\section{Ethics statement}

All methods were carried out in accordance with guidelines of CPCSEA (Committee for the Purpose of Control and Supervision on Experiments on Animals) with due approval from the Institutional Animal Ethics Committee (IAEC) of ICAR-National Dairy Research Institute, Karnal, Haryana with approval number (F.No. 43-IAEC-18-36), dated 13.10.2018). The experimental animals used to obtain ovaries for this study were native Indian buffaloes breed 'Murrah'. Efforts were made to minimize animals' pain and suffering in abattoir at Delhi, India. Also, we tried to reduce the number of buffaloes required to complete this study.

\section{Sample collection}

This study is based on buffalo embryos produced under in vitro conditions. No in vivo trials were carried out in any experiment. The present study involves two experimental groups' i.e. cloned embryos and IVF embryos of buffalo. Cloned embryos were collected at different developmental stages (2-cell, 8-cell and blastocyst) at different interval post in vitro culture. Embryos produced by IVF (2-cell, 8-cell and blastocyst) were used as control in this study. Embryos used for global DNA methylation analysis were produced under same season to nullify effect of season variation.

The morphological and physiological evaluation was done before selecting oocytes. Compact cumulus-oocyte-complexes (COCs) with 2-8 mm diameter in size, unexpanded cumulus mass having $\geq 2$ layers of cumulus cells, and with homogenous, evenly granular ooplasm were used for cloning and IVF purpose. Brilliant Cresyl Blue (BCB) stain was used to select oocytes with high developmental competence. After in vitro culture, cloned embryos at 2-cell, 8-cell and blastocyst stage were collected at 14-16 h, 36-40 h and $8^{\text {th }}$ day post in vitro culture (IVC), respectively. The embryos were washed thrice with DEPC-treated water and stored at $-196^{\circ} \mathrm{C}$ in liquid nitrogen until further use. IVF embryos at 2-cell, 8-cell and blastocyst stage were collected at $24-26 \mathrm{~h}, 68-72 \mathrm{~h}$ and $8^{\text {th }}$ day post IVC, respectively.

In this study, the total number of cell present in each pool of 2-cell, 8-cell and blastocysts stage produced by Hand-guided cloning and IVF was 1000,1000 and 6000 respectively for MeDIP-Seq. For bisulfite sequencing PCR, blastocyst stage of cloned and IVF embryos were collected that contained 6000 number of cells per pool. The donor cells used for HMC had been collected by biopsy of tail skin of bull No. Mu-4093, and were obtained from ICAR-Central Institute for Research on Buffaloes (CIRB), Hisar, in a cryopreserved form. Cryopreserved semen from the same bull (Mu-4093) was used for producing IVF embryos. Methods involved in vitro production of cloned and IVF embryos is described below.

\section{Chemicals}

All the chemicals and media were purchased from Sigma- Aldrich Corp., (St. Louis, MO, USA), and all the plasticware was purchased from Becton, Dickinson and Co., (Lincoln Park, NJ, USA) or Nunc (Rosklide, Denmark) unless mentioned otherwise. Fetal bovine serum (FBS) was obtained from Gibco Life technology (Gaithersburg, MD, USA) whereas, Research Vitro Cleave medium (K-RVCL), was purchased from William A. Cook (Brisbane, Australia). In vitro maturation (IVM) and fertilization (IVF) of oocytes, in vitro culture (IVC) of presumptive zygotes produced by IVF and reconstructed embryos produced by $\mathrm{HMC}$ and culture of somatic cells were carried out in a $\mathrm{CO} 2$ incubator ( $5 \% \mathrm{CO} 2$ in air, $90-95 \%$ relative humidity.

\section{In vitro embryo production by $\mathrm{HMC}$ and IVF}

Buffalo ovaries from the slaughterhouse were aspirated for Cumulus-oocyte complexes (COCs). COCs were classified into useable and unusable categories based on their morphological appearance as ones with evenly granular homogenous ooplasm and unexpanded cumulus mass with $\geq 2$ layers of cumulus cells are considered as useable. The oocytes which were wholly or partially denuded of the cumulus mass or which had expanded cumulus mass or irregular ooplasm were classified as non-useable. For selection of COCs of high developmental competence, those of useable category were stained with Brilliant Cresyl Blue (BCB), as described previously ${ }^{62}$. COCs with distinct blue colour (BCBp) were washed several times with the IVM medium, which consisted of TCM-199 + 10\% FBS p $5 \mathrm{mg} / \mathrm{mL}$ porcine follicle stimulating hormone $(\mathrm{pFSH})+\mathrm{I} \mathrm{mg} / \mathrm{mL}$ estradiol- $17 \beta+0.81 \mathrm{mM}$ sodium pyruvate $+50 \mathrm{mg} / \mathrm{mL}$ gentamicin sulfate. For IVM, the COCs were placed in $100 \mathrm{~mL}$ droplets of the IVM medium (15-20 COCs per droplet), overlaid with sterile mineral oil in $35 \mathrm{~mm}$ Petri dishes and cultured in a $\mathrm{CO} 2$ incubator at $38.5^{\circ} \mathrm{C}$ for 21 hours. Culture of donor cells to full confluence to synchronize them in $\mathrm{G} 1$ stage of cell cycle and all other procedures of HMC were carried out as described previously ${ }^{65}$. For production of IVF embryos, oocytes were subjected to IVM for $24 \mathrm{~h}$ as described above. IVF and IVC were carried out as described previously ${ }^{66}$. Semen of the same buffalo bull, the somatic cells of which had been used for HMC, was used for IVF for producing genetically half-identical IVF blastocysts. 


\section{DNA extraction}

Total DNA was isolated from respective pools of cloned and IVF embryos using Arcturus ${ }^{\circledR}$ PicoPure ${ }^{\circledR}$ DNA Extraction Kit (Arcturus, Mountain View, CA, USA, catalogue no.KIT0103) according to the manufacturer's instructions. Briefly, each pool of embryos (2-cell, 8-cell and blastocysts) was transferred to $1.5 \mathrm{~mL}$ DEPC-treated tube and was pelleted by centrifugation. The supernatant was removed and the pellet was resuspended in $150 \mu \mathrm{l}$ of Extraction Solution. The suspension was mixed well by vortexing for a few minutes. The samples were then incubated in a dry bath at $65^{\circ} \mathrm{C}$ for $3 \mathrm{~h}$. The sample tubes were then incubated in a dry bath at $95^{\circ} \mathrm{C}$ for $10 \mathrm{~min}$ to inactivate Proteinase $\mathrm{K}$. The purified DNA thus obtained is ready to be used for further processing or can be stored at $-20^{\circ} \mathrm{C}$. DNA quality control analysis was carried using Invitrogen ${ }^{\text {TM }}$ Qubit $^{\text {TM }} 3$ Fluorometer.

\section{Immunoprecipitation of genomic DNA}

Methylated DNA Immunoprecipitation (MeDIP) Kit (Abcam-117133) was used according to manufacturer's instructions to isolate methylated DNA from the embryo samples. Special low DNA LoBind tubes (Ep- pendorf \#022431021) were used during the MeDIP procedure to prevent loss of DNA. Initially, sonicated DNA (25 ng from each pool) was diluted in $450 \mu \mathrm{L}$ of TE buffer $\left(10 \mathrm{mM}\right.$ Tris- $\mathrm{HCl}, 1 \mathrm{mM}$ EDTA, pH 8.0) and then denatured at $95^{\circ} \mathrm{C}$ for 10 min. A portion of the sonicated DNA was reserved as Input (control) and was not subjected to immunoprecipitation. The denatured DNA was placed on ice for 10 min and was then incubated with $5 \mathrm{mC}$ monoclonal antibody for $2 \mathrm{~h}$ at $4^{\circ} \mathrm{C}$ with overhead shaking.

\section{MeDIP-Sequencing}

\section{Library preparation and quality control}

Global DNA methylation analysis of Handmade cloned and IVF embryos at 2-cell, 8-cell and blastocyst stages was done using MeDIP-Seq by a commercial service provider, M/S DNA Xpert, New Delhi, India.

Illumina library preparation was performed by using the NEBNext Ultra DNA Library Prep Kit for Illumina (NEB, New England Biolabs Inc., USA \#E7370S). Sonicated DNA (25ng from each pool) was end repaired into dA-tailed fragments. Then the NEBNext-indexed adaptor was ligated into sonicated DNA fragments. Adaptor-ligated DNA was further cleaned up by AMPure XP beads (Beckman Coulter, Inc., Life Sciences, United States \#A63881) and then subjected to the MeDIP procedure. The Input DNA was linked to different index primers. After immunoprecipitation, adaptor-ligated DNA was extracted by phenol/chloroform and precipitated by ethanol. The antibody-enriched DNA was subsequently amplified by using an index primer and universal PCR primer provided in NEB Multiplex Oligos for Illumina. PCR was performed with 20 cycles for each MeDIP sample. The PCR products were then purified by AMPure XP beads and eluted with TE buffer. The library concentration and size distribution was analyzed by Agilent 4200 Tapestation.The library was run on Agilent 4200 Tape Station and the resulting profile was evaluated. QC-passed libraries (peak size varies from 28 to 400 bp) were used to generate high-quality reads for further analysis.

\section{Sequencing and quality control}

The QC-passed were then set up on Illumina HiSeq 2500 platform for sequencing. Quality check of raw reads was carried out using FastQC (v0.11.5). Based upon Phred score value, all the reads were found to be of good quality, therefore, no filtering was required for any of the samples. The QC-passed high-quality reads (Phred Score Cut off of Q 20) were used for further analysis.

\section{MeDIP-Seq data analysis}

R package MEDIPS. R (v3.6.3) and MEDIPS (v1.36.0) softwares was used for analysis of raw data. The MeDIP-Seq data analysis workflow employed in the present study consisted of following major steps viz., loading of raw data into MEDIPS software, quality check of data, identification of differentially methylated regions (DMRs) based upon fold change criteria and classification/clustering of genes. The gene ontology (GO) enrichment analysis and pathway analysis was done by using R package MEDIPS and Panther Classification System, respectively. The reads generated were aligned using bowtie2 (v2.2.8) software to Bos taurus reference genome, UMD 3.1.1. CpG islands of genome were identified using cpgiscan (v1.0). CpGi annotation for each sample was done by intersecting bam file against the cpgiscan bed output using bedtools. Distribution of CpGs and feature annotation at different components of genome (promoter,exon, intron and intergenic region) was done by using R package genomation. genomation (v1.16.0). Distribution of CpG islands and their methylation status in different repetitive elements of genome (LINE, SINE, repetitive DNA, LTR, simple repeats, low complexity repeats) was done by using RepeatMasker.

\section{Bisulfite sequencing PCR analysis}

Five gene regions were selected randomly to validate MeDIP-Seq data. For that, 25 blastocyst-stage for each cloned and IVF embryos were used for validation of MeDIP-Seq data by bisulfite sequencing PCR analysis. Genomic DNA was isolated from respective pools of cloned and IVF blastocyst-stage embryos using the DNeasy ${ }^{\circledR}$ Blood \& Tissue Kit (Qiagen, catalogue no. 69504) according to the manufacturer's instructions. The purified DNA thus obtained is ready to be used for further processing or can be stored at $-20^{\circ} \mathrm{C}$. DNA quality control analysis was carried on NanoDrop ${ }^{\mathrm{TM}} 2000$ (Thermo Scientific, USA). Bisulfite conversion of DNA samples isolated from cloned and IVF blastocyst-stage embryos was done using EZ DNA Methylation-Direct ${ }^{\text {TM }}$ Kit (Cat. No. D-5020, Zymo Research, Orange, CA, USA) according to the instruction manual, with minor modifications as detailed; Genomic DNA isolated using above protocol was used for bisulfite conversion. DNA $(20 \mu \mathrm{l})$ was added to $130 \mu \mathrm{l}$ of CT Conversion Reagent solution and was centrifuged briefly to ensure that there were droplets in the cap or on sides of the tube. The mixture was then heated in a thermal cycler at $98^{\circ} \mathrm{C}$ for 8 min and $64^{\circ} \mathrm{C}$ for $3.5 \mathrm{~h}$ and was then stored at $4^{\circ} \mathrm{C}$ for up to 20 h. Bisulfite converted DNA was desalted, purified and eluted with $40 \mu \mathrm{l}$ of elution buffer. The O.D. of the bisulfite-converted DNA was recorded. Consequently, bisulfite sequencing PCR (BSP) was carried out with $1 \mu$ l of modified DNA per PCR reaction Meth-primers for selected five genes were designed from The Li 
Lab (MethPrimer) software at 2KB upstream regions covering at least one $\mathrm{CpG}$ island. For designing bisulfite PCR primers, the sequences for each gene were taken from NCBI (www.ncbi.nlm.nih.gov). The sequences of the BSP primers used to amplify the targeted products are shown in (Supplementary sheet S1). Hotstart PCR was carried out for bisulfite-converted DNA pairs using Hotstart DNA polymerase (Zymo Taq ${ }^{\text {TM }}$ premix, Zymo Research). The amplified product was taken as template DNA (with 1:5 dilution) for second PCR amplification with the same primers. The PCR cycle included denaturation for 10 min at $95^{\circ} \mathrm{C}$ followed by 35 repeated cycles of $95^{\circ} \mathrm{C}$ for $30 \mathrm{~s}$, annealing at variable temperatures for $30 \mathrm{~s}$ and extension at $72^{\circ} \mathrm{C}$ for $30 \mathrm{~s}$ followed by a final extension at $72^{\circ} \mathrm{C}$ for $10 \mathrm{~min}$. Resulting PCR products were run on $2 \%$ agarose gel to confirm the amplicon size. Purification of the bisulfite-treated amplified product was done with GeneJET PCR Purification Kit (Thermo Fisher Scientific, Inc. USA \#K0701). Purified PCR products were sent for custom sequencing to M/S DNA Xpert Pvt. Ltd., (New Delhi, India). The PCR products were sequenced in triplicates with both forward and reverse primers of selected region of interest. The data files generated with Sanger sequencing were processed using the Sequencing Analysis V5.3 software. Sequences with non-overlapping peaks are considered to be good for further analysis. Peaks with high background of $<50 \%$ of the co-efficient of variation (CV) are also considered to be good for further analysis. By using Seq Scanner, PDF and Fasta files were created from ABI files. Analysis of data generated for calculating methylation level (\%) and creating lollipop diagrams for each sample was done by using BioEdit version 7.2.5 software.

\section{Results}

Under this study, global DNA methylation profile of pre-implantation buffalo embryos at 2-cell, 8-cell and blastocyst stages, produced by HMC and IVF, was generated by MeDIP-Seq for comparing the differentially methylated regions (DMRs) between cloned and IVF embryos at each developmental stage.

\section{Production of cloned and IVF embryos at 2-cell, 8-cell and blastocyst stage}

In this experiment, somatic cells from an adult bull (Mu-4093) were used for the production of cloned embryos at 2-cell, 8-cell and blastocyst stages by HMC. Semen obtained from the same bull was used for the production of IVF embryos at each of these stages (Fig. 1). This was done to minimize the genetic variability between the cloned and IVF embryos since the embryos of the two groups produced in this manner were genetically half-identical.

It has been reported that incompetent embryos possess different epigenetic status from that of competent ones ${ }^{47}$. Therefore, it is necessary that competent and good quality embryos are used for MeDIP-SEq. We achieved this by two means. Firstly, we selected only those embryos which appeared to be morphologically normal in appearance. Second, we selected oocytes of high developmental competence for cloning and IVF by staining them with BCB. It has been shown in a previous study in our laboratory that the blastocyst rate was higher for BCB+ (oocytes with high developmental competence) than for BCB(oocytes with low developmental competence) oocytes. Moreover, the blastocysts produced from BCB + oocytes had inner cell mass (ICM) cell number, ICM/trophectoderm (TE) cell number ratio, global level of H3K18ac, apoptotic index and expression level of $B C L-X L$ similar to that of blastocysts produced through IVF ${ }^{48}$. Therefore, BCB + blastocysts had better developmental competence and were closer to IVF blastocysts in terms of quality, epigenetic status and gene expression than BCB- blastocysts, In view of this, only BCB + oocytes were used for HMC and IVF in the present study.

\section{Global mapping of DNA methylation of cloned and IVF buffalo embryos}

In the present study, $130 \mathrm{~GB}$ MeDIP-Seq data was generated from three developmental stages (2-cell, 8-cell and blastocyst stages) of buffalo embryos produced by HMC and IVF. The number of total raw reads generated for cloned embryos (at 2-cell, 8-cell and blastocyst stage) was 466,173,180, whereas, the corresponding number for IVF embryos was $441,935,854$. For all the samples, 86 to $94.4 \%$ of the total reads got aligned against the reference genome of Bos taurus, UMD 3.1.1 (Fig. 2). The alignment statistics of the three biological replicates each of cloned and IVF embryos are given in Table 1. 
Table 1

Alignment statistics of reads generated for cloned and IVF 2-cell stage, 8-cell and blastocyst stage embryos.

\begin{tabular}{|c|c|c|c|c|c|}
\hline Sample & Reads & Read Length (bp) & No. of reads & Total bases & $\begin{array}{l}\text { Total bases } \\
\text { (GB) }\end{array}$ \\
\hline \multirow[t]{2}{*}{$2 \mathrm{CC}-1$} & $\mathrm{R} 1$ & 51 & 24780895 & 1263825645 & 1.26 \\
\hline & $\mathrm{R} 2$ & 51 & 24780895 & 1263825645 & 1.26 \\
\hline \multirow[t]{2}{*}{$2 \mathrm{CC}-2$} & $\mathrm{R} 1$ & 51 & 23273355 & 1186941105 & 1.18 \\
\hline & $\mathrm{R} 2$ & 51 & 23273355 & 1186941105 & 1.18 \\
\hline \multirow[t]{2}{*}{$2 \mathrm{CC}-3$} & $\mathrm{R} 1$ & 51 & 23780105 & 1212785355 & 1.21 \\
\hline & $\mathrm{R} 2$ & 51 & 23780105 & 1212785355 & 1.21 \\
\hline \multirow[t]{2}{*}{$2 \mathrm{Cl}-1$} & $\mathrm{R} 1$ & 51 & 25003135 & 1275159885 & 1.27 \\
\hline & $\mathrm{R} 2$ & 51 & 25003135 & 1275159885 & 1.27 \\
\hline \multirow[t]{2}{*}{$2 \mathrm{Cl}-2$} & $\mathrm{R} 1$ & 51 & 24348045 & 1241750295 & 1.24 \\
\hline & $\mathrm{R} 2$ & 51 & 24348045 & 1241750295 & 1.24 \\
\hline \multirow[t]{2}{*}{$2 \mathrm{Cl}-3$} & $\mathrm{R} 1$ & 51 & 23824520 & 1215030520 & 1.21 \\
\hline & $\mathrm{R} 2$ & 51 & 23824520 & 1215030520 & 1.21 \\
\hline \multirow[t]{2}{*}{$8 C C-1$} & $\mathrm{R} 1$ & 51 & 25313412 & 1290984012 & 1.29 \\
\hline & $\mathrm{R} 2$ & 51 & 25313412 & 1290984012 & 1.29 \\
\hline \multirow[t]{2}{*}{$8 \mathrm{CC}-2$} & $\mathrm{R} 1$ & 51 & 24503121 & 1249659171 & 1.24 \\
\hline & $\mathrm{R} 2$ & 51 & 24503121 & 1249659171 & 1.24 \\
\hline \multirow[t]{2}{*}{$8 C C-3$} & $\mathrm{R} 1$ & 51 & 26201037 & 1336252887 & 1.33 \\
\hline & $\mathrm{R} 2$ & 51 & 26201037 & 1336252887 & 1.33 \\
\hline \multirow[t]{2}{*}{$8 \mathrm{Cl}-1$} & $\mathrm{R} 1$ & 51 & 24068996 & 1227518796 & 1.22 \\
\hline & $\mathrm{R} 2$ & 51 & 24068996 & 1227518796 & 1.22 \\
\hline \multirow[t]{2}{*}{$8 \mathrm{Cl}-2$} & $\mathrm{R} 1$ & 51 & 24287010 & 1238637510 & 1.23 \\
\hline & $\mathrm{R} 2$ & 51 & 24287010 & 1238637510 & 1.23 \\
\hline \multirow[t]{2}{*}{$8 \mathrm{Cl}-3$} & $\mathrm{R} 1$ & 51 & 25020386 & 1276039686 & 1.27 \\
\hline & $\mathrm{R} 2$ & 51 & 25020386 & 1276039686 & 1.27 \\
\hline \multirow[t]{2}{*}{ CBL-1 } & $\mathrm{R} 1$ & 51 & 25532920 & 1302178920 & 1.3 \\
\hline & $\mathrm{R} 2$ & 51 & 25532920 & 1302178920 & 1.3 \\
\hline \multirow[t]{2}{*}{ CBL-2 } & $\mathrm{R} 1$ & 51 & 24870380 & 1268389380 & 1.26 \\
\hline & $\mathrm{R} 2$ & 51 & 24870380 & 1268389380 & 1.26 \\
\hline \multirow[t]{2}{*}{ CBL-3 } & $\mathrm{R} 1$ & 51 & 24012535 & 1224639285 & 1.22 \\
\hline & $\mathrm{R} 2$ & 51 & 24012535 & 1224639285 & 1.22 \\
\hline \multirow[t]{2}{*}{ BLI-1 } & $\mathrm{R} 1$ & 51 & 28927270 & 1475290770 & 1.47 \\
\hline & $\mathrm{R} 2$ & 51 & 28927270 & 1475290770 & 1.47 \\
\hline \multirow[t]{2}{*}{ BLI-2 } & $\mathrm{R} 1$ & 51 & 27463585 & 1400645835 & 1.4 \\
\hline & $\mathrm{R} 2$ & 51 & 27463585 & 1400645835 & 1.4 \\
\hline \multirow[t]{2}{*}{ BLI-3 } & $\mathrm{R} 1$ & 51 & 28843810 & 1471034310 & 1.47 \\
\hline & $\mathrm{R} 2$ & 51 & 28843810 & 1471034310 & 1.47 \\
\hline
\end{tabular}

\section{Chromosomal distribution of MeDIP-Seq reads}

The chromosomal distribution of the three biological replicates each of cloned and IVF 2-cell, 8-cell and blastocyst stage embryos is given in Fig. 3 (A, B, \& C). MeDIP-Seq reads were detected in most of chromosomal regions (chromosome 1-29 and chromosome X) at the 2-cell, 8-cell and blastocyst stage in both cloned and IVF embryos. Maximum number of reads was found to map on chromosome number 1. 


\section{Overall distribution of differentially methylated regions (DMRs)}

The percentage of distribution of DMRs throughout the three developmental stages examined i.e., 2-cell, 8-cell, and blastocyst stages in cloned and IVF embryos is given in (Fig. 4). In the cloned embryos, the number of hypermethylated CpGs sites which was high at the 2-cell stage, decreased sharply at the 8cell stage and then increased to the highest level at the blastocyst stage. In IVF embryos, hypermethylation of CpG sites increased from the 2-cell stage to the 8-cell stage and then declined sharply at the blastocyst stage. Also, hypermethylation of CpGs in cloned 2-cell and 8-cell stage embryos was significantly (padj < = 0.05) less than in IVF counterparts. The blastocyst stage of cloned embryos showed significantly (padj < = 0.05) higher numbers of hypermethylated CpGs sites. These results suggest that DNA methylation is altered dynamically throughout the developmental stages in cloned embryos in comparison with their IVF counterparts.

\section{Determination of DMRs at each developmental stages}

Total number of DMRs were detected at each developmental stage of cloned and IVF embryos. The average length of DMR was kept approximately 1999bp.The number of uniquely present DMRs in cloned and IVF embryos at 2-cell stage was found to be 90,501 (11.2\%) and 1,49,925 (18.6\%), respectively. From among the commonly present DMRs i.e., 5,66,734, a total of 2,81,276 were found to be hypermethylated in cloned relative to IVF embryos. The number of uniquely present DMRs in cloned and IVF embryos at 8-cell stage was found to be $68,826(14.7 \%)$ and 1,78,171 (38\%), respectively. From among the commonly present DMRs i.e., 2,21,383, a total of 1,04,174 were found to be hypermethylated in cloned relative to IVF embryos.

The number of uniquely present DMRs in cloned and IVF embryos was 1,49,797 (18.4\%) and 1,02,839 (12.6\%) respectively, whereas, 5,62,134 were commonly expressed in the two groups. From among the commonly present DMRs 2,82,582 were hypermethylated in cloned relative to IVF embryos. The Venn diagrams showing the DMRs commonly present in cloned and IVF 2-cell, 8-cell and blastocyst stage embryos and the DMRs uniquely present in the two groups are presented in (Fig. 5A, B, \& C).

Distribution of DMRs at gene level

Genes which overlap with HMRs in the promoter or gene-body regions are considered as methylated genes. If for HMRs coverage, edge R. logFC $=+1$ then the gene is designated as hypermethylated and if edge $\mathrm{R}$. $\log \mathrm{FC}=-1$, it is designated as unmethylated. In the present study, overall 27,518 genes were identified at the 2-cell stage, out of which 12,392 genes were found to be hypermethylated in cloned relative to IVF embryos. In case of 8-cell stage embryos, the total number of genes was found to be 23,621 of which, 14,594 genes were hypermethylated. Similarly, at the blastocyst stage, 24,556 genes were identified out of which, 9,111 genes were hypermethylated in cloned relative to IVF embryos (Fig. 6 (A, B, \& C), Table 2). The maximum number of hypermethylated genes was found at the 8-cell stage whereas, the minimum number was observed at the blastocyst stage. The number of genes showing differential methylation at 2-cell, 8-cell and blastocyst stage in cloned and IVF embryos is shown in (Table 3).

Table 2

Number of genes showing hypermethylation among embryos at 2-cell, 8-cell and blastocyst stage between cloned and IVF embryos.

\begin{tabular}{|lll|}
\hline Comparison & Total number of genes & Number of hypermethylated genes \\
\hline 2 CC vs $2 \mathrm{Cl}$ & 27518 & 12392 \\
\hline $8 \mathrm{CC}$ vs $8 \mathrm{Cl}$ & 23621 & 14594 \\
\hline CBL vs BLI & 24556 & 9111 \\
\hline
\end{tabular}

Table 3

Number of genes showing hypermethylation at 2-cell, 8-cell and blastocyst stage in cloned and IVF embryos.

\begin{tabular}{|ll|}
\hline Group & Number of hypermethylated genes \\
\hline Cloned 2-cell & 12392 \\
\hline Cloned 8-cell & 13179 \\
\hline Cloned blastocyst & 9111 \\
\hline IVF 2-cell & 10367 \\
\hline IVF 8-cell & 14594 \\
\hline IVF blastocyst & 7182 \\
\hline
\end{tabular}

\section{Distribution of DMRs in different components of the genome}

Genome-wide DNA methylation profile in cloned and IVF embryos was observed with the distribution of MeDIP-Seq reads in different component of genome including upstream and downstream $1 \mathrm{~KB}$ and $2 \mathrm{~KB}$ promotor, exons, introns, intergenic region, $\mathrm{CpG}$ islands and repetitive elements.

\section{2-cell stage}

Out of the 8,07,160 DMRs evaluated ( $P<0.05), 3,71,777$ DMRs were found to be hypermethylated in cloned relative to IVF 2-cell stage embryos. Out of the $3,71,777$ hypermethylated DMRs, a major part i.e., 3,62,323 (97.46\%) and 3,61,195 (97.15\%) DMRs belong to intergenic region at upstream and downstream $1 \mathrm{~Kb}$ and $2 \mathrm{~Kb}$, respectively. 


\section{8-cell stage}

Of 4,68,379 DMRs evaluated ( $P<0.05), 1,73,000$ DMRs were found to be hypermethylated in cloned relative to IVF 8 -cell stage embryos. Out of the $1,73,000$ hypermethylated DMRs, a major part i.e., 1,58,300 (91.5\%) and 1,56,768 (90.62\%) DMRs belong to intergenic region at upstream and downstream $1 \mathrm{~Kb}$ and $2 \mathrm{~Kb}$, respectively

\section{Blastocyst stage}

Out of the $8,14,770$ DMRs evaluated $(P<0.05), 4,32,379$ DMRs were found to be hypermethylated in cloned relative to IVF blastocyst stage embryos. Out of the 4,32,379 hypermethylated DMRs, a major part i.e., 4,24,218 (98.11\%) and 4,23,080 (97.85\%) DMRs belong to intergenic region at upstream and downstream $1 \mathrm{~Kb}$ and $2 \mathrm{~Kb}$, respectively. Venn diagram showing the distribution of hypermethylated DMRs in different genomic regions (promoter, exon, intron and intergenic) in cloned relative to IVF 2-, 8-cell and blastocyst stage embryos is presented in (Fig. 7). The number and percentage of hypermethylated DMRs in upstream and downstream $1 \mathrm{~Kb}$ and $2 \mathrm{~Kb}$, upstream $2 \mathrm{~Kb}$ and downstream $2 \mathrm{~Kb}$ in cloned relative to IVF 2-, 8-cell and blastocyst stage embryos is presented in (Table 4) respectively.

Table 4

Genomic distribution of hypermethylated DMRs in 2-cell, 8-cell and blastocyst stage embryos.

\begin{tabular}{|c|c|c|c|c|c|c|c|c|c|c|c|}
\hline \multirow[t]{3}{*}{ Comparison } & \multirow[t]{3}{*}{ Methylation } & \multirow[t]{3}{*}{ Features } & \multirow{3}{*}{$\begin{array}{l}\text { Total } \\
\text { DMRs } \\
(\mathrm{P}< \\
0.05)\end{array}$} & \multicolumn{2}{|c|}{$\begin{array}{l}\text { Upstream and } \\
\text { downstream } 1 \mathrm{~Kb}\end{array}$} & \multicolumn{2}{|c|}{$\begin{array}{l}\text { Upstream and } \\
\text { downstream } 2 \mathrm{~Kb}\end{array}$} & \multicolumn{2}{|c|}{ Upstream 2kb } & \multicolumn{2}{|c|}{$\begin{array}{l}\text { Downstream } \\
2 \mathrm{~Kb}\end{array}$} \\
\hline & & & & DMRs & DMRs & DMRs & DMRs & DMRs & DMRs & DMRs & DMRs \\
\hline & & & & & (\%) & & (\%) & & $(\%)$ & & $(\%)$ \\
\hline \multirow[t]{5}{*}{$2 \mathrm{CC}$ vs $2 \mathrm{Cl}$} & \multirow[t]{5}{*}{ Hypermethylation } & Total & $3,71,777$ & & & & & & & & \\
\hline & & Promoter & & 3,213 & 0.86 & 4,927 & 1.33 & 3,270 & 0.88 & 3,246 & 0.87 \\
\hline & & Exon & & 3,412 & 0.92 & 2,999 & 0.81 & 3,981 & 1.07 & 3,029 & 0.81 \\
\hline & & Intron & & 2,829 & 0.76 & 2,656 & 0.71 & 2,952 & 0.79 & 2,666 & 0.72 \\
\hline & & Intergenic & & $3,62,323$ & 97.46 & $3,61,195$ & 97.15 & $3,61,574$ & 97.26 & $3,62,836$ & 97.6 \\
\hline \multirow[t]{5}{*}{$8 \mathrm{CC}$ vs $8 \mathrm{Cl}$} & \multirow[t]{5}{*}{ Hypermethylation } & Total & $1,73,000$ & & & & & & & & \\
\hline & & Promoter & & 7,407 & 4.28 & 10,297 & 5.95 & 7,173 & 4.15 & 7,298 & 4.22 \\
\hline & & Exon & & 4,561 & 2.64 & 3,594 & 2.08 & 5,701 & 3.3 & 3,713 & 2.15 \\
\hline & & Intron & & 2,732 & 1.58 & 2,341 & 1.35 & 3,042 & 1.76 & 2,365 & 1.37 \\
\hline & & Intergenic & & $1,58,300$ & 91.5 & $1,56,768$ & 90.62 & $1,57,084$ & 90.8 & $1,59,624$ & 92.27 \\
\hline \multirow{5}{*}{$\begin{array}{l}\text { 2CBL vs } \\
2 \mathrm{BLI}\end{array}$} & \multirow[t]{5}{*}{ Hypermethylation } & Total & $4,32,379$ & & & & & & & & \\
\hline & & Promoter & 3,085 & 0.71 & 4,717 & 1.09 & 3,133 & 0.72 & 3,161 & 0.73 & 3,085 \\
\hline & & Exon & 2,836 & 0.66 & 2,487 & 0.58 & 3,398 & 0.79 & 2,505 & 0.58 & 2,836 \\
\hline & & Intron & 2,240 & 0.52 & 2,095 & 0.48 & 2,326 & 0.54 & 2,106 & 0.49 & 2,240 \\
\hline & & Intergenic & $4,24,218$ & 98.11 & $4,23,080$ & 97.85 & $4,23,522$ & 97.95 & $4,24,607$ & 98.2 & $4,24,218$ \\
\hline
\end{tabular}

\section{CpG islands in cloned and IVF embryos}

Analysis of the percentage of reads which mapped distinctly with CpGs islands (CGIs) in all the biological replicates of cloned and IVF embryos at 2-cell, 8-cell and blastocyst stage showed a range of $10.95-22.91 \%$ (Fig. 8). Maximum percentage of reads which mapped with CGIs for three biological replicates of cloned and IVF embryos at 2-cell stage was $11 \%$ and $16.62 \%$, respectively. Similarly, for 8 -cell stage cloned and IVF embryos, it was found to be $22.91 \%$ and $16.37 \%$, whereas, in case of blastocysts, the corresponding values were $16.39 \%$ and $17.87 \%$, respectively. In the present study, the total number of $\mathrm{CpG}$ islands distributed in buffalo embryo genome were observed. For the first time, we identified total 2,17,246 CpG islands, out of which 1,04,188 (42.55\%) and 1,13,058 $(48.07 \%)$ islands were present in cloned and IVF embryos, respectively (Table 5$)$. In the cloned embryos, 52,168 (23.72\%) were found to be hypermethylated, whereas, the corresponding figures in IVF embryos were 41,365 (30.25\%). The number and percentage of CpG islands hypermethylated in cloned versus IVF embryos at each developmental stage (i.e., $2 \mathrm{CC}$ vs $2 \mathrm{Cl}, 8 \mathrm{CC}$ vs $8 \mathrm{Cl}, \mathrm{CBL}$ vs $\mathrm{BLI}$ ) is given in (Table 6). 
Table 5

Number of $\mathrm{CpG}$ islands showing hypermethylation in 2-cell, 8-cell and blastocyst stage cloned

\begin{tabular}{|llll|}
\hline Group & Methylation & Number of CpG islands & \% of total CpGs islands \\
\hline Cloned 2-Cell & Hypermethylation & 8290 & 2.23 \\
\hline Cloned 8-Cell & Hypermethylation & 32715 & 18.91 \\
\hline Cloned blastocyst & Hypermethylation & 11163 & 2.58 \\
\hline IVF 2-Cell & Hypermethylation & 5895 & 2.1 \\
\hline IVF 8-Cell & Hypermethylation & 25745 & 24.71 \\
\hline IVF blastocyst & Hypermethylation & 9725 & 3.44 \\
\hline
\end{tabular}

Table 6

Number of $\mathrm{CpG}$ islands showing hypermethylation between cloned and IVF embryos at 2-cell, 8-cell and blastocyst stage.

\begin{tabular}{|llll|}
\hline Sample & Methylation & Number of CpG islands & \% CpGs islands \\
\hline 2CC-vs-2Cl & Hypermethylation & 8290 & 2.23 \\
\hline 8CC-vs-8Cl & Hypermethylation & 32715 & 18.91 \\
\hline CBL-vs-BLI & Hypermethylation & 11163 & 2.58 \\
\hline
\end{tabular}

\section{CpG enrichment in cloned and IVF embryos}

The assessment of $\mathrm{CpGs}$ enrichment value of methylated regions (frequency of $\mathrm{CpGs}$ wise) was done by dividing the relative frequency of $\mathrm{CpGs}$ (region.relH) of the regions by the relative frequency of $\mathrm{CpGs}$ (genome.relH) of the reference genome. Similarly, the final value of $\mathrm{CpGs}$ enrichment of methylated regions (ratio $\mathrm{CpG}$ wise) was done by dividing the observed/expected ratio of $\mathrm{CpGs}$ within the region (region.goge) by the observed/expected ratio of $\mathrm{CpGs}$ within the reference genome (genome.goge). The enrichment score for both frequency $\mathrm{CpGs}$ and ratio $\mathrm{CpGs}$ in the genomic regions sequenced compared to the reference genome was above 1 in all the cases (Table 7), indicating a successful enrichment of methylated fragments in the data sets.

Table 7

CpG enrichment of methylated regions in 2-cell, 8-cell and blastocyst stage of cloned and IVF embryos.

\begin{tabular}{|c|c|c|c|c|}
\hline Group & $\begin{array}{l}\text { Relative frequency of } \mathrm{CpGs} \text { within the } \\
\text { Regions. (Region.relH) }\end{array}$ & $\begin{array}{l}\text { Observed/expected ratio of CpGs within the } \\
\text { regions (Region.goge) }\end{array}$ & $\begin{array}{l}\text { Ratio of region.relH/ } \\
\text { genome.relH } \\
\text { (enrichment. } \\
\text { score.relH) }\end{array}$ & $\begin{array}{l}\text { Ratio of region.goge/ } \\
\text { genome.goge } \\
\text { (enrichment. } \\
\text { score.goge) }\end{array}$ \\
\hline $\begin{array}{l}\text { Cloned 2- } \\
\text { cell }\end{array}$ & 2.262895 & 0.4060407 & 2.194193 & 1.695227 \\
\hline $\begin{array}{l}\text { Cloned 8- } \\
\text { cell }\end{array}$ & 2.993334 & 0.4425746 & 2.902455 & 1.847757 \\
\hline $\begin{array}{l}\text { Cloned } \\
\text { blastocyst }\end{array}$ & 3.831625 & 0.546323 & 3.715295 & 2.280909 \\
\hline $\begin{array}{l}\text { IVF } \\
\text { 2-cell }\end{array}$ & 2.899797 & 0.4578469 & 2.811758 & 1.911519 \\
\hline $\begin{array}{l}\text { IVF } \\
\text { 8-cell }\end{array}$ & 3.156285 & 0.4815534 & 3.060459 & 2.010494 \\
\hline $\begin{array}{l}\text { IVF } \\
\text { blastocyst }\end{array}$ & 2.932217 & 0.4758824 & 2.843193 & 1.986818 \\
\hline
\end{tabular}

\section{MA and Volcano plot of cloned vs IVF embryos at different developmental stages}

MA plot is commonly used to visualize the log fold change (FC) versus mean expression between two samples. It is a type of $2 \mathrm{D}$ scatter plot which allows visual display of base-2 log FC along the Y-axis and normalized mean expression along the $\mathrm{X}$-axis, where each data point represents single $\mathrm{CpG}$ site. In the present study, this plot has been used to visualize log FC versus mean expression between cloned relative to IVF embryos at different developmental stages. Each data point with extreme values on the $\mathrm{Y}$-axis represents the $\mathrm{CpGs}$ with significant differential methylation. Data points falling above the 1 threshold on the $\mathrm{Y}$-axis indicate significant number of $\mathrm{CpGs}$ which were hypermethylated whereas, those below - 1, indicate CpGs which were hypomethylated. The data points falling close to 0 on the $\mathrm{Y}$-axis indicates that both the samples share highly similar methylation pattern. Volcano plot is another type of scatter plot which allows quick visual identification of those data points ( $\mathrm{CpGs}$, genes etc.) that display changes of high magnitude which are statistically significant on plotting the measure of statistical significance ( $p$-value) against the magnitude of the change (FC). In the present study, this scatter plot has been used to predict the status of CpGs which are significantly differentially methylated, either hyper- or hypomethylated in cloned relative to IVF embryos at given stages of cloned and IVF embryos (Fig. 9A, B \& C). The CpGs sites seen dispersed towards the right side represent the hypermethylated sites, and those seen 
dispersed towards the left side represent the hypomethylated sites. The CpGs seen towards the top are those which are statistically most significantly differentially methylated.

\section{Distribution of $\mathrm{CpG}$ islands in repetitive elements of genome}

Distribution of $\mathrm{CpG}$ islands with hypermethylation in the repetitive elements of genome i.e., LINE, SINE, repetitive DNA, LTR, simple repeats and low complexity repeats etc. was examined between cloned and IVF embryos at different developmental stages and between different developmental stages (Table 8).

Relative percentage of $\mathrm{CpG}$ islands found in particular repeats in comparison with reference genome (UMD 3.1.1) at different developmental stages in cloned and IVF embryos is presented in (Fig. 10A, B, \& C). It was observed that at 2-, 8-cell and blastocyst stage cloned embryos, maximum distribution of CpGis was found in LTRs, simple repeats and LINE respectively.

Table 8

Number of $\mathrm{CpG}$ islands hypermethylation in repetitive elements of genome among embryos at 2-cell, 8-cell and blastocyst stage between cloned and IVF embryos.

\begin{tabular}{|llllllll|}
\hline Comparison & Methylation & LINE & SINE & Repetitive DNA & LTR & Simple Repeats & Low Complexity \\
\hline 2CC vs 2Cl & Hypermethylated & 806 & 606 & 270 & 133 & 2587 & 605 \\
\hline 8CC vs 8Cl & Hypermethylated & 84614 & 2870 & 974 & 324 & 15324 & 168 \\
\hline CBL vs BLI & Hypermethylated & 1069 & 575 & 314 & 309 & 1603 & 344 \\
\hline
\end{tabular}

Gene ontology (GO) analysis of cloned embryos relative to IVF embryos

GO analysis was done in order to explore the biological significance, detailed annotation of gene function, biological process and cellular distribution of differentially methylated genes between cloned and IVF embryos. GO analysis is based on a controlled vocabulary of terms of three domains - "Biological Process" (BP), "Molecular Function" (MF) and "Cellular Compartment" (CC) ${ }^{49}$. Using GO terms, MeDIP-Seq results can be summarized to provide insights into the methylation status of genes between cloned and IVF embryos. In the present study, genes with hypermethylation (Edge R. Log fold change $\geq+1)$ in cloned relative to IVF embryos were used for GO analysis.

\section{GO analysis of cloned vs IVF embryos at the 2-cell stage}

A total of 483 Biological Process categories were found to be affected. The categories most enriched under Biological Process GO term were- cellular process, biological process, regulation of biological process. Similarly, there were 85 enriched Molecular Function $\mathrm{GO}$ term categories, of which the most affected ones were- molecular function, binding and protein binding. In case of Cellular Component Go term, there were 121 enriched categories with cell part, cellular component, and intracellular anatomical structure being the most enriched ones (Fig. 11A). The functional annotations, which were found to be hypermethylated are given in (supplementary sheet S2).

\section{GO analysis of cloned vs IVF embryos at the 8-cell stage}

GO analysis of differentially methylated genes in cloned and IVF 8-cell stage embryos revealed a total of 526 Biological Process categories to be affected. The categories most enriched under Biological Process GO term were- biological process, cellular process and metabolic process. Similarly, there were 97 enriched Molecular Function GO term categories, of which the most affected ones were- molecular function, binding and protein binding. In case of Cellular Component GO term, there were 115 enriched categories with cellular component, cellular anatomical entity and intracellular anatomical structure being the most enriched ones (Fig. 11B). The functional annotations, which were most relevantly found to be hypermethylated are represented in (supplementary sheet S3).

\section{GO analysis of cloned vs IVF embryos at the blastocyst stage}

GO analysis revealed that a total of 594 Biological Process categories were affected in cloned relative to IVF embryos at the blastocyst stage. The categories most enriched under Biological Process GO term were- cellular process, regulation of biological process, regulation of cellular process. Similarly, there were 131 enriched Molecular Function GO term categories, of which the most affected ones were- molecular function, binding and protein binding. In case of Cellular Component GO term, there were 176 enriched categories with cellular component, cellular anatomical entity and cytoplasm being the most enriched ones (Fig. 11C). The functional annotations, which were most relevantly found to be hypermethylated are represented in (supplementary sheet S4).

\section{Pathways affected in cloned relative to IVF embryos}

At 2-cell stage cloned embryos, total 30 pathways were detected, out of which 15 pathways were affected by hypermethylation of genes related to embryonic development relative to IVF counterparts. Out of 28 pathways detected, 15 pathways were affected by hypermethylation of genes related to embryonic development in 8-cell stage cloned relative to IVF embryos. At blastocyst stage cloned embryos, 37 pathways were found, of which 27 pathways were affected by hypermethylation of genes related to embryonic development relative to IVF embryo (Table 9). Wnt signaling pathway, inflammation mediated by chemokine and integrin signaling pathway and gonadotropin-releasing hormone receptor pathway were majorly affected by hypermethylation of DNA throughout the developmental stages. 
Table 9

Pathways affected by hypermethylation of genes in cloned relative to IVF at 2-cell, 8-cell and blastocyst stage embryos.

\section{2-CELL STAGE}

\begin{tabular}{|c|c|c|c|}
\hline Pathways affected by hypermethylation & No. of genes & $P$ value & FDR \\
\hline Integrin signalling pathway (P00034) & 162 & 7.13E-05 & $5.95 \mathrm{E}-03$ \\
\hline Inflammation mediated by chemokine and cytokine signaling pathway (P00031) & 197 & $5.62 \mathrm{E}-04$ & 3.13E-02 \\
\hline Gonadotropin-releasing hormone receptor pathway (P06664) & 193 & 8.59E-04 & 3.59E-02 \\
\hline PDGF signaling pathway (P00047) & 120 & 2.15E-03 & 7.20E-02 \\
\hline CCKR signaling map (P06959) & 140 & $2.28 \mathrm{E}-03$ & $6.35 \mathrm{E}-02$ \\
\hline Endothelin signaling pathway (P00019) & 73 & 4.51E-03 & $1.08 \mathrm{E}-01$ \\
\hline Apoptosis signaling pathway (P00006) & 106 & $5.45 \mathrm{E}-03$ & 1.14E-01 \\
\hline Ras Pathway (P04393) & 62 & 1.13E-02 & 2.10E-01 \\
\hline Angiogenesis (P00005) & 129 & 1.36E-02 & 2.27E-01 \\
\hline Wnt signaling pathway (P00057) & 200 & $1.56 \mathrm{E}-02$ & 2.36E-01 \\
\hline T cell activation (P00053) & 72 & 2.19E-02 & 3.04E-01 \\
\hline EGF receptor signaling pathway (P00018) & 111 & 2.35E-02 & 3.02E-01 \\
\hline B cell activation (P00010) & 58 & $2.63 \mathrm{E}-02$ & $3.14 \mathrm{E}-01$ \\
\hline Heterotrimeric G-protein signaling pathway-Gq alpha and Go alpha mediated pathway (P00027) & 91 & $3.82 \mathrm{E}-02$ & 4.25E-01 \\
\hline Histamine $\mathrm{H} 1$ receptor mediated signaling pathway (P04385) & 39 & 3.90E-02 & 4.07E-01 \\
\hline \multicolumn{4}{|l|}{ 8-CELL STAGE } \\
\hline Angiogenesis (P00005) & 165 & 4.38E-04 & $3.65 \mathrm{E}-02$ \\
\hline Integrin signalling pathway (P00034) & 177 & 5.97E-04 & 3.33E-02 \\
\hline PDGF signaling pathway (P00047) & 139 & 1.99E-03 & $8.32 \mathrm{E}-02$ \\
\hline CCKR signaling map (P06959) & 158 & 4.36E-03 & $1.46 \mathrm{E}-01$ \\
\hline Wnt signaling pathway (P00057) & 236 & 8.09E-03 & $2.25 \mathrm{E}-01$ \\
\hline Gonadotropin-releasing hormone receptor pathway (P06664) & 207 & 1.27E-02 & 3.02E-01 \\
\hline Alzheimer disease-presenilin pathway (P00004) & 110 & 1.59E-02 & 3.32E-01 \\
\hline Ras Pathway (P04393) & 69 & $1.98 \mathrm{E}-02$ & 3.67E-01 \\
\hline EGF receptor signaling pathway (P00018) & 127 & $3.11 \mathrm{E}-02$ & 5.19E-01 \\
\hline Endothelin signaling pathway (P00019) & 76 & 3.49E-02 & 5.30E-01 \\
\hline Apoptosis signaling pathway (P00006) & 113 & $3.63 \mathrm{E}-02$ & 5.05E-01 \\
\hline Oxytocin receptor mediated signaling pathway (P04391) & 59 & 4.03E-02 & 5.17E-01 \\
\hline PI3 kinase pathway (P00048) & 56 & 4.48E-02 & 5.34E-01 \\
\hline Oxidative stress response (P00046) & 56 & 4.48E-02 & 4.99E-01 \\
\hline 5HT2 type receptor mediated signaling pathway (P04374) & 67 & 4.72E-02 & 4.93E-01 \\
\hline \multicolumn{4}{|l|}{ BLASTOCYST STAGE } \\
\hline Inflammation mediated by chemokine and cytokine signaling pathway (P00031) & 156 & $8.20 \mathrm{E}-05$ & $6.85 \mathrm{E}-03$ \\
\hline Wnt signaling pathway (P00057) & 168 & $2.71 \mathrm{E}-04$ & $1.51 \mathrm{E}-02$ \\
\hline Endothelin signaling pathway (P00019) & 62 & 4.57E-04 & 1.91E-02 \\
\hline Heterotrimeric G-protein signaling pathway-Gq alpha and Go alpha mediated pathway (P00027) & 83 & 4.92E-04 & $1.64 \mathrm{E}-02$ \\
\hline Integrin signalling pathway (P00034) & 115 & $9.68 \mathrm{E}-04$ & $2.69 \mathrm{E}-02$ \\
\hline Blood coagulation (P00011) & 44 & 2.10E-03 & $5.00 \mathrm{E}-02$ \\
\hline Nicotinic acetylcholine receptor signaling pathway (P00044) & 66 & $2.52 \mathrm{E}-03$ & $5.25 \mathrm{E}-02$ \\
\hline PDGF signaling pathway (P00047) & 90 & $3.24 \mathrm{E}-03$ & $6.02 \mathrm{E}-02$ \\
\hline
\end{tabular}




\begin{tabular}{|c|c|c|c|}
\hline \multicolumn{4}{|l|}{ 2-CELL STAGE } \\
\hline Angiogenesis (P00005) & 102 & 4.10E-03 & $6.85 \mathrm{E}-02$ \\
\hline DNA replication (P00017) & 4 & 5.33E-03 & 8.09E-02 \\
\hline lonotropic glutamate receptor pathway (P00037) & 39 & 5.61E-03 & 7.81E-02 \\
\hline Heterotrimeric G-protein signaling pathway-Gi alpha and Gs alpha mediated pathway (P00026) & 99 & 7.23E-03 & 9.29E-02 \\
\hline Alzheimer disease-amyloid secretase pathway (P00003) & 45 & 8.11E-03 & 9.67E-02 \\
\hline EGF receptor signaling pathway (P00018) & 86 & 1.19E-02 & $1.32 \mathrm{E}-01$ \\
\hline Nicotine pharmacodynamics pathway (P06587) & 28 & $1.28 \mathrm{E}-02$ & $1.34 \mathrm{E}-01$ \\
\hline Gonadotropin-releasing hormone receptor pathway (P06664) & 134 & 1.31E-02 & $1.29 \mathrm{E}-01$ \\
\hline Metabotropic glutamate receptor group I pathway (P00041) & 21 & 1.37E-02 & 1.27E-01 \\
\hline Alzheimer disease-presenilin pathway (P00004) & 73 & 1.44E-02 & 1.27E-01 \\
\hline Histamine $\mathrm{H} 1$ receptor mediated signaling pathway (P04385) & 32 & 1.57E-02 & $1.31 \mathrm{E}-01$ \\
\hline Metabotropic glutamate receptor group III pathway (P00039) & 46 & $1.98 \mathrm{E}-02$ & $1.58 \mathrm{E}-01$ \\
\hline Cadherin signaling pathway (P00012) & 70 & 3.19E-02 & 2.42E-01 \\
\hline 5HT2 type receptor mediated signaling pathway (P04374) & 45 & 3.34E-02 & 2.42E-01 \\
\hline Axon guidance mediated by netrin (P00009) & 26 & 3.51E-02 & $2.44 \mathrm{E}-01$ \\
\hline Oxytocin receptor mediated signaling pathway (P04391) & 39 & 3.64E-02 & 2.43E-01 \\
\hline Insulin/IGF pathway-protein kinase B signaling cascade (P00033) & 27 & 4.45E-02 & $2.86 \mathrm{E}-01$ \\
\hline B cell activation (P00010) & 42 & 4.73E-02 & 2.92E-01 \\
\hline Plasminogen activating cascade (P00050) & 17 & 4.94E-02 & $2.95 \mathrm{E}-01$ \\
\hline
\end{tabular}

\section{Methylation status of important genes involved in embryonic development in cloned relative to IVF embryos}

Methylation status of some important genes involved in embryonic development viz. pluripotency-related genes, imprinted genes, apoptosis-related genes, cell cycle-related genes, methylation-specific genes and some functionally important genes is given in (Table 10). A particular gene is depicted as hypermethylated if it overlaps with highly methylated region (HMR) even in a single gene region. However, the actual genes expression level of a particular gene can vary irrespective of presence of methylation in any region of that gene. There is a complex relationship between DNA methylation and gene expression as higher gene expression levels are generally linked with low methylation at promotor region but higher gene body methylation 50,51 . The exact expression status of a gene can be known only after examining the correlation of DNA methylation with mRNA expression profile of that particular gene. 
Table 10

Methylation status of genes related to embryonic development in blastocyst stage cloned embryos relative to IVF counterparts.

\begin{tabular}{|c|c|c|c|c|c|}
\hline \multirow{2}{*}{$\begin{array}{l}\text { Gene } \\
\text { symbol }\end{array}$} & \multirow[t]{2}{*}{ Gene name } & \multirow{2}{*}{$\begin{array}{l}\text { Chromosomal } \\
\text { location }\end{array}$} & \multicolumn{3}{|c|}{ No. of regions hypermethylated at } \\
\hline & & & $\begin{array}{l}2 \text {-cell } \\
\text { stage }\end{array}$ & $\begin{array}{l}\text { 8-cell } \\
\text { stage }\end{array}$ & $\begin{array}{l}\text { Blastocyst- } \\
\text { stage }\end{array}$ \\
\hline POU2F1 & POU domain, class 2 , transcription factor 1 & GK000003.2 & 12 & 03 & 03 \\
\hline NANOG & Nanog homeobox & GK000005.2 & 0 & 01 & 0 \\
\hline$K L F 4$ & Kruppel-like factor 4 & GK000008.2 & 02 & 03 & 0 \\
\hline TCF3 & $\begin{array}{l}\text { Transcription factor } 3 \text { (E2A immunoglobulin enhancer-binding factors } \\
\text { E12/E47) }\end{array}$ & GK000007.2 & 04 & 07 & 02 \\
\hline LIN28b & Lin-28 Homolog B & GK000009.2 & 07 & 0 & 07 \\
\hline TDGF1 & Teratocarcinoma-derived growth factor 1 & GK000002.22 & 02 & 01 & 0 \\
\hline SALL4 & Spalt Like Transcription Factor 4 & GK000001.23 & 06 & 08 & 0 \\
\hline DUSP1 & Dual specificity protein phosphatase 1 & GK000001.29 & 22 & 43 & 06 \\
\hline DUSP6 & Dual specificity protein phosphatase 6 & GK000005.2 & 0 & 03 & 0 \\
\hline FGF4 & Fibroblast Growth Factor 4 & GK000002.29 & 0 & 0 & 0 \\
\hline GRB10 & Growth factor receptor-bound protein 10 & GK000004.2 & 18 & 22 & 03 \\
\hline PEG10 & Paternally expressed gene 10 & GK000004.2 & 02 & 02 & 01 \\
\hline MEST & Mesoderm Specific Transcript & GK000004.2 & 02 & 02 & 01 \\
\hline IGF2R & Insulin-like growth factor 2 receptor & GK000009.2 & 17 & 28 & 03 \\
\hline$M A O A$ & Monoamine oxidase A & GK000030.2 & 10 & 04 & 08 \\
\hline GNAS & Guanine nucleotide-binding protein & GK000001.23 & 07 & 14 & 0 \\
\hline$N D N$ & Necdin & GK000002.21 & 0 & 01 & 0 \\
\hline PHLDA2 & Pleckstrin Homology Like Domain Family A Member 2 & GK000002.29 & 0 & 0 & 0 \\
\hline CDKN1C & Cyclin Dependent Kinase Inhibitor $1 \mathrm{C}$ & GK000002.29 & 0 & 02 & 0 \\
\hline PLAG1 & Pleomorphic adenoma gene 1 & GK000001.24 & 0 & 01 & 0 \\
\hline ASCL2 & Achaete-scute complex homolog 2 & GK000002.29 & 0 & 01 & 0 \\
\hline CASP9 & Caspase 9 & GK000001.26 & 02 & 03 & 03 \\
\hline$B A X$ & Bcl-2-associated X protein & GK000001.28 & 01 & 03 & 0 \\
\hline$B A D$ & BCL2-antagonist of cell death & GK000002.29 & 01 & 06 & 0 \\
\hline$B C L 2 L 1$ & BCL2-like 1 & GK000001.23 & 06 & 22 & 0 \\
\hline$D F F A$ & DNA Fragmentation Factor Subunit Alpha & GK000001.26 & 01 & 04 & 02 \\
\hline FAS & Fas cell surface death receptor & GK000002.26 & 03 & 05 & 04 \\
\hline APAF1 & Apoptotic protease activating factor 1 & GK000005.2 & 10 & 03 & 02 \\
\hline HSPA1A & Heat Shock Protein Family A (Hsp70) Member 1A & GK000002.23 & 01 & 02 & 0 \\
\hline PTEN & Phosphatase and tensin homolog & GK000002.26 & 19 & 03 & 03 \\
\hline MDM2 & Mouse double minute 2 homolog & GK000005.2 & 03 & 05 & 01 \\
\hline CDK4 & Cyclin Dependent Kinase 4 & GK000005.2 & 0 & 03 & 0 \\
\hline NPAT & Nuclear Protein, Coactivator Of Histone Transcription & GK000001.25 & 05 & 01 & 01 \\
\hline DNMT1 & DNA Methyltransferase 1 & GK000007.2 & 05 & 06 & 0 \\
\hline DNMTЗA & DNA Methyltransferase 3A & GK000001.21 & 01 & 12 & 0 \\
\hline DNMT3B & DNA Methyltransferase 3B & GK000001.23 & 05 & 06 & 0 \\
\hline TET1 & Tet methylcytosine dioxygenase 1 & GK000002.28 & 27 & 32 & 0 \\
\hline TET2 & Tet methylcytosine dioxygenase 2 & GK000006.2 & 10 & 02 & 03 \\
\hline TET3 & Tet methylcytosine dioxygenase 3 & GK000001.21 & 07 & 21 & 01 \\
\hline
\end{tabular}




\begin{tabular}{|c|c|c|c|c|c|}
\hline \multirow{2}{*}{$\begin{array}{l}\text { Gene } \\
\text { symbol }\end{array}$} & \multirow[t]{2}{*}{ Gene name } & \multirow{2}{*}{$\begin{array}{l}\text { Chromosomal } \\
\text { location }\end{array}$} & \multicolumn{3}{|c|}{ No. of regions hypermethylated at } \\
\hline & & & $\begin{array}{l}2 \text {-cell } \\
\text { stage }\end{array}$ & $\begin{array}{l}\text { 8-cell } \\
\text { stage }\end{array}$ & $\begin{array}{l}\text { Blastocyst- } \\
\text { stage }\end{array}$ \\
\hline EZH2 & Enhancer Of Zeste 2 Polycomb Repressive Complex 2 Subunit & GK000004.2 & 08 & 06 & 0 \\
\hline MBD3 & Methyl-CpG Binding Domain Protein 3 & GK000007.2 & 02 & 01 & 0 \\
\hline$Y Y 1$ & Yin Yang 1 & GK000002.21 & 04 & 12 & 0 \\
\hline TIMP2 & TIMP Metallopeptidase Inhibitor 2 & GK000001.29 & 03 & 09 & 02 \\
\hline$B M P 7$ & Bone Morphogenetic Protein 7 & GK000001.23 & 07 & 03 & 18 \\
\hline$A Q P 9$ & Aquaporin 9 & GK000001.20 & 02 & 0 & 03 \\
\hline SOD1 & Superoxide Dismutase 1 & GK000001.2 & 02 & 04 & 0 \\
\hline FGF7 & Fibroblast Growth Factor 7 & GK000001.20 & 11 & 01 & 09 \\
\hline IL6 & Interleukin 6 & GK000004.2 & 02 & 02 & 0 \\
\hline G6PD & Glucose-6-Phosphate Dehydrogenase & GK000030.2 & 02 & 07 & 0 \\
\hline MTPN & Myotrophin & GK000004.2 & 08 & 20 & 01 \\
\hline WNT2 & Wnt Family Member 2 & GK000004.2 & 06 & 06 & 08 \\
\hline DKK3 & Dickkopf WNT Signaling Pathway Inhibitor 3 & GK000001.25 & 07 & 05 & 09 \\
\hline COL4A1 & Collagen Type IV Alpha 1 Chain & GK000001.22 & 02 & 27 & 11 \\
\hline TCF7 & Transcription Factor 7 & GK000007.2 & 02 & 06 & 03 \\
\hline CRABP2 & Cellular Retinoic Acid Binding Protein 2 & GK000003.2 & 0 & 02 & 02 \\
\hline PPARA & Peroxisome Proliferator Activated Receptor Alpha & GK000005.2 & 07 & 02 & 21 \\
\hline PCGF2 & Polycomb Group Ring Finger 2 & GK000001.29 & 01 & 01 & 0 \\
\hline MCL1 & Induced myeloid leukemia cell differentiation protein-1 & GK000003.2 & 01 & 03 & 0 \\
\hline DYSF & Dysferlin & GK000001.21 & 10 & 11 & 53 \\
\hline HDAC8 & Histone Deacetylase 8 & GK000030.2 & 30 & 20 & 03 \\
\hline LEF1 & Lymphoid Enhancer Binding Factor 1 & GK000006.2 & 20 & 08 & 13 \\
\hline IFN- $\tau$ & Interferon tau & GK000008.2 & 02 & 09 & 0 \\
\hline
\end{tabular}

\section{Bisulfite sequencing PCR}

To confirm the results of MeDIP-Seq data, five genes (IGF2R, PEG10, MDM2, TCG7 and COL4A1) were selected randomly. Primers bisulfite sequencing PCR were designed using MethPrimer software. The total of number of blastocysts used for bisulfite sequencing PCR in cloned and IVF groups was 25 for each group. Each sample was sequenced in triplicate. Data generated from Sanger sequencing was analysed by BioEdit version 7.2.5. All the five gene regions which had showed hypermethylation in cloned relative to IVF embryos in MeDIP-Seq data, showed hypermethylation in bisulfite sequencing PCR also which validated and confirmed the reliability of our data obtained from MeDIP-Seq (Fig. 12).

\section{Discussion}

Although, some reports are available in bovine and other species on the DNA methylation in cloned compared to IVF embryos at different developmental stages, these reports provide a limited insight on the aberrations in DNA methylation in cloned embryos since low throughput techniques like immunostaining and RT-PCR were used for examining the methylation status in these studies ${ }^{52,53,54}$. To our information, there is no report in any species on the complete comparative global DNA methylation profile of cloned and IVF embryos at different developmental stages using a high throughput technique like MeDIP-Seq.

Over the years, many methods have been developed for analyzing genome-wide DNA methylome. These include whole genome bisulfite sequencing (WGBS), reduced representation bisulfite sequencing (RRBS), TET-assisted bisulfite sequencing (TAB-seq), comprehensive high-throughput arrays for relative methylation (CHARM), methylation array and MeDIP-SEq. However, each method has its own merits and demerits when it comes to sequence whole genome. WGBS is considered to be the best method for examination of DNA methylation profile of mammalian genome due to its high resolution. But it is costly, time consuming and generates complicated data that further needs comprehensive bioinformatics analysis which limits the popularity of this technique. MeDIPSeq is a widely used affinity-based method for examining DNA methylation. Global DNA methylation analysis is feasible with MeDIP-Seq even with very low amount of starting (as low as $1 \mathrm{ng}$ ) DNA sample ${ }^{55,56}$. Many recent studies have used MeDIP-Seq to generate relative genome-wide DNA methylation profile $51,57,58$. Therefore, we selected this method to study genome-wide DNA methylation in cloned embryos in comparison with IVF embryos in buffalo.

In the present study, we reported for the first time, genome-wide DNA methylome in cloned and IVF embryos. We generated 130 GB data from two types of embryos (cloned and IVF) each at 2-cell, 8-cell and blastocyst stages. The total number of CpG islands (CpGis) in the genome was found to be 2,17,246 out of 
which 1,04,188 islands belonged to cloned embryos and 1,13,058 to IVF embryos CpG islands related to cloned embryos showed much higher methylation when compared with IVF counterparts. Distribution of hypermethylated CpGs sites was found to be more prevalent in the 2-cell stage embryos (46.06 \%), which reduced at the 8-cell stage (36.94\%) and was highest at the blastocyst stage $(53.07 \%)$ in cloned relative to IVF embryos. Distribution of CpG islands in the repetitive elements of the genome (i.e. LINE, SINE, repetitive DNA, LTR, simple repeats \& low complexity DNA) was found to different for different developmental stage of cloned and IVF embryos. At 2-cell stage embryos, maximum distribution of CpGis was observed in LTRs (23.8\%) in cloned group compared to $30.4 \%$ for the IVF counterparts. Cloned embryos at the 8-cell stage showed maximum distribution of CpGis in simple repeats (21.3\%) whereas, the IVF counterparts showed it in LTRs (19.3\%). Blastocyst-stage embryos had major distribution of CpGis in LINE (25.4\%) in cloned and low complexity DNA (18.8\%) in IVF embryos.

A total of $8,07,160$ DMRs were identified at the 2-cell stage in cloned embryos out of which, maximum number of DMRs were found to be hypermethylated with respect to IVF counterparts. However, the difference in the magnitude of hypermethylation in the two groups of embryos decreased significantly at the 8cell stage followed by a significant increase at the blastocyst stage. It was observed that a major portion of hypermethylated DMRs belonged to intergenic region at upstream and downstream $1 \mathrm{~KB}$ and $2 \mathrm{~KB}$ region of genome at each developmental stage. Finally, we validated our MeDIP-Seq data by carrying out direct bisulfite sequencing PCR with randomly selected genes irrespective of their methylation status.

An unusual pattern of de-methylation and re-methylation in cloned embryos has been reported in several 5-methylcytosine immunofluorescence-based studies in past years $46,52,53,54$. Our study was not immunofluorescence-based but our MeDIP-Seq data is in agreement with the results of these low-throughput studies as cloned embryos showed hypermethylation of DNA at blastocyst stage in comparison to IVF counterparts.

Dean et al. (2001) ${ }^{54}$ reported that cloned bovine embryos lack passive demethylation mechanism and have high expression of $D N M T 3 A$ and $D N M T 3 B$ which is responsible for de novo methylation at 4-cell and 8-cell stages. Likewise, in the present study, 23,621 genes were identified at the 8-cell stage in cloned embryos out of which 14,594 showed hypermethylation. This scenario reflects re-methylation of genes due to re-establishment of methylation marks that coincides with time of embryonic genome activation (EGA). Memili et al. (2000) ${ }^{59}$ suggested the same possible reason for this pattern of methylation at 8 cell stage as this stage involves major change in transcriptional activation of the embryonic genome which might activate Dnmt3a and Dnmt3b enzymes.

Dean et al. (2001) ${ }^{54}$ reported increased methylation level in the bovine blastocyst stage embryos specifically in the trophectoderm cells. Contrary to this, we found that the less number of genes were showing hypermethylation (9111) in cloned embryos relative to IVF embryos at the blastocyst stage.

Using single-cell RRBS to generate DNA methylomes for SCNT embryos in mice, Liu et al. (2016) ${ }^{60}$ reported abnormally high levels of DNA methylation in 2cell and 4-cell stage SCNT embryos. It was found that, SCNT embryos at 4-cell stage were relatively hypermethylated compared with 2-cell stage embryos which opposed the demethylation pattern of normal embryos. Also, the aberrant DNA methylation in arrested SCNT embryos was attributed to differences in expression of Dnmt1 and Tet1 enzymes. However, our study showed a slightly different trend as we found that 27,517 genes were identified in 2-cell stage cloned embryo, with 12,392 genes showing hypermethylation at 2-cell stage cloned embryos in comparison to IVF counterparts. This suggests that the majority of genes undergo demethylation at early developmental stages during nuclear reprogramming. In our data, DNMT1 and TET1 showed hypermethylation which could be the reason for lower methylation level of genes in 2-cell stage cloned embryos relative to their IVF counterparts. It is suggested that cytoplasmic factors of oocytes might help in triggering demethylation with remodelling of chromatin.

To our information, there is only one study in which genome-wide DNA methylation has been studied in SCNT preimplantation embryos but it is focused on specific parts of genome. Zhang et al. (2016) ${ }^{46}$ compared DNA methylation reprogramming in bovine SCNT and IVF preimplantation embryos and analyzed the influence of vitamin $\mathrm{C}(\mathrm{VC})$ on the reprogramming of DNA methylation by using bisulfite sequencing. The results showed that global DNA methylation followed a typical pattern of demethylation and remethylation in IVF preimplantation embryos however, the global genome remained hypermethylated in SCNT preimplantation embryos. Compared with the IVF group, pluripotency genes POU5F1 and NANOG showed insufficient demethylation and hypermethylation in the SCNT group. Similarly, in our study, we found that pluripotency genes (POU5F1, TCF3, LIN28b, and DUSP1) showed high number of regions with hypermethylation which suggests lower expression of these genes.

Gene ontology analysis (GO) of differentially methylated genes in the present study showed 483 biological process, 85 molecular function and 121 cellular components to be affected by hypermethylation of genes in cloned 2-cell stage embryos relative to their IVF counterparts. Similarly, in the 8-cell stage cloned embryos, 526 biological process, 97 molecular function and 115 cellular components were found to be affected by hypermethylation of genes with respect to IVF embryos. GO analysis for cloned blastocyst-stage embryos relative to IVF embryos revealed 594 biological process, 131 molecular function and 176 cellular component to be affected by hypermethylation.

In the present study, 15 pathways were found to be affected at the 2-cell stage, 15 at the 8-cell stage and 27 at the blastocyst stage in cloned embryos relative to IVF counterparts. For all the developmental stages covered under present study, the major pathways affecting embryonic development in cloned embryos relative to IVF counterparts were found to be Wnt signaling pathway, inflammation mediated by chemokine \& cytokine signalling pathways, gonadotropinreleasing hormone receptor pathway and Integrin signalling pathway. These pathways were affected by hypermethylation of DNA.

It was found in the present study that imprinting genes such as IGF2R, PEG10, GRB10, MEST, and MAOA showed presence of hypermethylated regions that suggest lower gene expression at the blastocyst stage in cloned relative to IVF embryos. Some important apoptosis-related genes such as $C A S P 9$ and $D F F A$, FAS, APAF1, and PTEN were found to have hypermethylation in gene region in blastocyst stage cloned embryos compared to their IVF counterparts.

Similarly, cell cycle-related genes such as MDM2, and NPAT showed presence of hypermethylation in gene regions in blastocyst stage cloned embryos relative to IVF counterparts. 
We found that the methylation status of methylation-specific genes viz. DNMT1, DNMT3A, DNMT3B, TET1, EZH2, and MBD3 showed no methylation in gene regions with whereas TET2 and TET3 gene found to have hypermethylation in gene regions in blastocyst stage cloned embryos relative to their IVF counterparts. This pattern of methylation reflects high expression of abovementioned genes in the cloned blastocyst-stage embryos which might be responsible for the abnormal hypermethylation observed in cloned blastocysts in comparison with IVF counterparts.

There are some functionally important genes which contribute to embryonic development in bovine embryos. We found that $Y Y 1$, SOD1, IL6, G6PD, PCGF2, $M C L 1$, and IFN- $\tau$ represented no methylation in the gene regions whereas TIMP2, MTPN, COL4A1, TCF7, AQP9, BMP7, FGF7, WNT2, DKK3, CRABP2, PPARA, $D Y S F, \angle E F 1$ and HDAC8 showed high number of regions with hypermethylation in blastocyst stage cloned embryos compared to their IVF counterparts. Shyam et al. (2020) ${ }^{61}$ also observed a high expression of WNT signalling pathway genes i.e. TCF7 and LEF1 in cloned buffalo blastocyst-stage embryos. They also reported lower gene expression level of IFN- $\tau$ (primary maternal signal for recognition of pregnancy in ruminants) in cloned blastocyst was lower than in IVF counterparts.

Similarly, Sood et al. (2019) ${ }^{62}$ also reported down- regulated expression of IFN- $\tau$ in cloned embryos in comparison with IVF counterparts. In contrast, present study indicates hypermethylation of TCF7 and LEF1 at gene level which suggests lower expression of these genes in cloned embryos. Also, we found the gene region for IFN- $\tau$ to be unmethylated which points to a high expression of this gene in cloned compared to IVF embryos. Thus, our results regarding methylation status of TCF7, LEF1 and IFN- $\tau$ genes were found to be not in agreement with above mentioned studies.

Kim et al. (2009) ${ }^{63}$ reported abnormally up-regulated expression of tissue inhibitor of metalloproteinase-2 (TIMP-2) and superoxide dismutase (SOD) in the placentae of SCNT cloned Korean native cattle that died immediately after birth and in normal placentae obtained by artificial insemination. Abnormal expression of these two genes reported to be partly responsible to for abnormal placental function and low survivability of cloned claves. Results from our study regarding these two gene showed that showed hypermethylation in gene region of TIMP-2 gene and no methylation in gene regions of SOD1 gene in cloned blastocysts relative to IVF counterparts. For TIMP2 gene, our results are not in agreement with those of above study but our results for SOD1 gene, are in agreement with above study as its unmethylated status can suggesting high level of gene expression.

Gene such as $A Q P 9$ encode a water channels protein which is involved in coordinating urea transport. Gao et al. (2019) ${ }^{64}$ reported abnormally lower expression level of $A Q P 9$ gene in placenta of SCNT cattle by both RNA-seq and q-PCR. Similarly, in present study, methylation level of $A Q P 9$ gene was found to be very high which suggests lower expression level of this gene in cloned embryos relative to IVF counterparts. Sood et al. (2019) ${ }^{62}$ also reported downregulated expression of $D K K 3$ gene in cloned embryos in comparison with IVF embryos. Likewise, our study showed high number of hypermethylated regions of $D K K 3$ gene in cloned blastocysts relative to IVF counterparts that might indicate towards low expression level of this gene. This study can be sum up with the following conclusions: there is a profound difference in the global DNA methylation profile between cloned and IVF embryos. These differences are manifested throughout the course of embryonic development. Cloned embryos differ from their IVF counterparts in the enriched GO terms of Biological Process, Molecular Function and Cellular Component categories in terms of the differentially methylated regions in cloned and IVF embryos. A large number of pathways are affected by hypermethylation in cloned relative to IVF embryos. Among these, the major pathways related to embryonic development are Integrin signalling pathway, Wnt signaling pathway, apoptosis signaling pathway, inflammation mediated by chemokine \& cytokine signaling pathway, gonadotropin-releasing hormone receptor pathway, CCKR signaling map, angiogenesis. There is a need of further more targeted studies stimulated by this study to evaluate exact genomic locations, genes and other factors that are responsible for low efficiency of blastocyst rate and live birth rate of cloned offsprings.

\section{Declarations}

\section{Acknowledgments}

S. Malpotra was supported by fellowship from ICMR, Ministry of Health \& Family Welfare, Govt. of India., P. Goel was recipient of fellowship from ICAR-NDRI, Karnal and S. Shyam was supported by fellowship from NFHST, Ministry of Tribal Affairs, Govt. of India. We are thankful to Dr. P. Palta for valuable guidance and support with the research project.

\section{Author's contribution}

S. M. wrote the manuscript, P.G, S.S, and M.K.S contributed to lab related work and P.P contributed to designing the project and provided guidance.

\section{Funding}

This work was financially supported by Indian Council of Agricultural Research-National Agricultural Science Fund (ICAR-NASF) (Grant No. NASF/GTR7004/2018-19), Government of India.

\section{Conflict of interest statement}

None declared.

\section{Data availability}

The high-throughput sequencing data (Raw data/ FastQ) have been submitted in NCBI's

Sequence Read Archive (SRA) under BioProject ID: PRJNA723972. 


\section{References}

1. Wilmut, I., Schnieke, A. E., McWhir, J., Kind, A. J. \& Campbell, K. H. Viable offspring derived from fetal and adult mammalian cells. Nature. 385 (6619), 810-813 (1997).

2. Keefer, C. L. (2015) Artificial cloning of domestic animals. Proceedings of the National Academy of Sciences, 112(29), 8874-8878.

3. Niemann, H. \& Lucas-Hahn, A. Somatic cell nuclear transfer cloning: practical applications and current legislation. Reprod. Domest. Anim. 47, 2-10 (2012).

4. Galli, C. et al. Somatic cell nuclear transfer and transgenesis in large animals: current and future insights. Reprod. Domest. Anim. 47, 2-11 (2012).

5. Akagi, S., Geshi, M. \& Nagai, T. Recent progress in bovine somatic cell nuclear transfer. Anim. Sci. J. 84 (3), 191-199 (2013).

6. Ogura, A., Inoue, K. \& Wakayama, T. Recent advancements in cloning by somatic cell nuclear transfer. Philos. T. R. Soc. B. 368 (1609), 20110329 (2013).

7. Loi, P., luso, D., Czernik, M. \& Ogura, A. A new, dynamic era for somatic cell nuclear transfer? Trends in biotechnology. 34 (10), $791-797$ (2016).

8. Czernik, M., Anzalone, D. A., Palazzese, L., Oikawa, M. \& Loi, P. Somatic cell nuclear transfer: failures, successes and the challenges ahead. Int. J. Dev. Biol. $63(3-4-5), 123-130(2019)$.

9. Campbell, K. H. et al. Somatic cell nuclear transfer: past, present and future perspectives. Theriogenology. 68 (1), $214-231$ (2007).

10. Panarace, M. et al. How healthy are clones and their progeny: 5 years of field experience. Theriogenology. 67 (1), 142-151 (2007).

11. Rodriguez-Osorio, N., Urrego, R., Cibelli, J. B., Eilertsen, K. \& Memili, E. Reprogramming mammalian somatic cells. Theriogenology. 78 (9), $1869-1886$ (2012).

12. Loi, P., Modlinskia, J. A. \& Ptak, J. Interspecies somatic cell nuclear transfer: a salvage tool seeking first aid. Theriogenology. 76, 217-228 (2011).

13. Saini, M. et al. An update: Reproductive handmade cloning of water buffalo (Bubalus bubalis). Anim. Reprod. Sci. 197, 1-9 (2018).

14. Selokar, N. L. et al. Cloning of buffalo, a highly valued livestock species of south and southeast Asia: any achievements? Cell. Reprogram. 20 (2), 89-98 (2018).

15. Young, L. E., Sinclair, K. D. \& Wilmut, I. Large offspring syndrome in cattle and sheep. Rev. Reprod. 3, 155-163 (1998).

16. Hill, J. R. et al. Evidence for placental abnormality as the major cause of mortality in first-trimester somatic cell cloned bovine fetuses. Biol. Reprod. $\mathbf{6 3}$ (6), 1787-1794 (2000)

17. Heyman, Y. et al. Frequency and occurrence of late-gestation losses from cattle cloned embryos. Biol. Reprod. 66 (1), 6-13 (2002).

18. Yang, X. et al. Nuclear reprogramming of cloned embryos and its implications for therapeutic cloning. Nat. Genet. 39 (3), $295-302$ (2007).

19. Wells, D. N. Nuclear transfer: the importance of donor and recipient cells for nuclear reprogramming and cloning efficiency in mammals. Acta. Sci. Vet. 38 , 487-507 (2010).

20. Aguiar, L. H. et al. Quality assessment of goat oocytes and effects on goat cloning efficiency after in vivo or in vitro maturation. Anim. Reprod. 13, A297 (abstract). (2016)

21. Panda, S. K. et al. Effect of cytoplasmic volume on developmental competence of buffalo (Bubalus bubalis) embryos produced through hand-made cloning. Cell. Reprogram. 13 (3), 257-262 (2011).

22. Campbell, K. H. S. et al. Cloning: eight years after Dolly. Reprod. Domest. Anim. 40, 256-268 (2005).

23. Zhai, Y. et al. Epigenetic states of donor cells significantly affect the development of somatic cell nuclear transfer (SCNT) embryos in pigs. Mol. Reprod. Dev. 85 (1), 26-37 (2018).

24. Bertolini, L. R. et al. Animal cloning: survival of the fittest. Ciência Animal. 22 (1), 82-105 (2012).

25. Niemann, H., Tian, X. C., King, W. A. \& Lee, R. S. Epigenetic reprogramming in embryonic and foetal development upon somatic cell nuclear transfer cloning. Reproduction. 135, 151-163 (2008).

26. Niemann, H. Epigenetic reprogramming in mammalian species after SCNT-based cloning. Theriogenology. 86, 80-90 (2016).

27. Bannister, A. J. \& Kouzarides, T. Regulation of chromatin by histone modifications. Cell Res. 21, 381-395 (2011).

28. Ibeagha-Awemu, E. M. \& Zhao, X. Epigenetic marks: regulators of livestock phenotypes and conceivable sources of missing variation in livestock improvement programs. Front. Genet. 6, 302 (2015).

29. González-Recio, O., Toro, M. A. \& Bach, A. Past, present, and future of epigenetics applied to livestock breeding. Front. Genet. 6, 305 (2015).

30. Santos, F., Hendrich, B., Reik, W. \& Dean, W. Dynamic reprogramming of DNA methylation in the early mouse embryo. Dev. Biol. 241, 172-182 (2002).

31. Sarmento, O. F. et al. Dynamic alterations of specific histone modifications during early murine development. J. Cell Sci. 117, 4449-4459 (2004).

32. Bird, A. P. \& Wolffe, A. P. Methylation-induced repression- belts, braces, and chromatin. Cell. 99, 451-454 (1999).

33. Bestor, T. H. The DNA methyltransferases of mammals. Hum. Mol. Genet. 9, 2395-2402 (2000).

34. Bird, A. DNA methylation patterns and epigenetic memory.. Genes Dev. 16, 6-21 (2002).

35. Simonsson, S. \& Gurdon, J. DNA demethylation is necessary for the epigenetic reprogramming of somatic cell nuclei. Nat. Cell Biol. 6, 984-990 (2004).

36. Niwa, H., Miyazaki, J. \& Smith, A. G. Quantitative expression of Oct-3/4 defines differentiation, dedifferentiation or self-renewal of ES cells. Nat. Genet. 24, 372-376 (2000).

37. Bourc'his, D. et al. Delayed and incomplete reprogramming of chromosome methylation patterns in bovine cloned embryos. Curr. Biol. 11 (19), 15421546 (2001). 
38. Beaujean, N. et al. Effect of limited DNA methylation reprogramming in the normal sheep embryo on somatic cell nuclear transfer. Biol. Reprod. 71, 185193 (2004).

39. Couldrey, C. \& Lee, R. S. DNA methylation patterns in tissues from mid-gestation bovine foetuses produced by somatic cell nuclear transfer show subtle abnormalities in nuclear reprogramming. BMC Dev. Biol. 10, 27 (2010).

40. Peat, J. R. \& Reik, W. Incomplete methylation reprogramming in SCNT embryos. Nat. Genet. 44, 965-966 (2012).

41. Chan, M. M., Smith, Z. D., Egli, D., Regev, A. \& Meissner, A. Mouse ooplasm confers context-specific reprogramming capacity. Nat. Genet. 44 (9), 978 (2012).

42. Chen, T. et al. The DNA methylation events in normal and cloned rabbit embryos. FEBS letters. 578 (1-2), 69-72 (2004).

43. Koike, T. et al. DNA Methylation errors in cloned mouse sperm by germ line barrier evasion. Biol. Reprod. 94 (6), 128 (2016).

44. Duan, J. E. et al. Methylome dynamics of bovine gametes and in vivo early embryos. Front. Genet. 10, 512 (2019).

45. Jiang, Z. et al. DNA methylomes of bovine gametes and in vivo produced preimplantation embryos. Biol. Reprod. 99 (5), $949-959$ (2018).

46. Zhang, S. et al. Aberrant DNA methylation reprogramming in bovine SCNT preimplantation embryos. Sci. Rep. 6, 30345 (2016).

47. Sood, T. J. et al. RNA sequencing and transcriptome analysis of buffalo (Bubalus bubalis) blastocysts produced by somatic cell nuclear transfer and in vitro fertilization. Mol. Reprod. Dev. 86 (9), 1149-1167 (2019).

48. Selokar, N. L. et al. Hope for restoration of dead valuable bulls through cloning using donor somatic cells isolated from cryopreserved semen. PloS One. 9 , e90755 (2014).

49. Rashmi, Sah, S., Shyam, S., Singh, M. K. \& Palta, P. Treatment of buffalo (Bubalus bubalis) SCNT embryos with microRNA-21 mimic improves their quality and alters gene expression but does not affect their developmental competence. Theriogenology. 126, 8-16 (2019).

50. Su, J. et al. Oocytes selected using BCB staining enhance nuclear reprogramming and the in vivo development of SCNT embryos in cattle. PloS one. 7 (4), e36181 (2012).

51. Mohapatra, S. K. et al. Establishment of trophectoderm cell lines from buffalo (Bubalus bubalis) embryos of different sources and examination of in vitro developmental competence, quality, epigenetic status and gene expression in cloned embryos derived from them. PLoS One. 10 (6), e0129235 (2015).

52. Ashburner, M. et al. Gene ontology: tool for the unification of biology. The Gene Ontology Consortium. Nat. Genet. 25( (1)), 25-29 (2000).

53. Kass, S. U., Landsberger, N. \& Wolffe, A. P. DNA methylation directs a time-dependent repression of transcription initiation. Curr. Boil. 7 (3), $157-165$ (1997).

54. Huang, Y. Z. et al. Genome-wide DNA methylation profiles and their relationships with mRNA and the microRNA transcriptome in bovine muscle tissue (Bos taurine). Sci. Rep. 4, 6546 (2014).

55. Santos, F. et al. Epigenetic marking correlates with developmental potential in cloned bovine preimplantation embryos. Curr. Biol. 13, 1116-1121 (2003).

56. Suteevun, T. et al. Epigenetic characteristics of cloned and in vitro-fertilized swamp buffalo (Bubalus bubalis) embryos. J. Anim. Sci. 84 (8), 2065-2071 (2006).

57. Dean, W. et al. (2001) Conservation of methylation reprogramming in mammalian development: aberrant reprogramming in cloned embryos. Proc. Natl. Acad. Sci. U. S. A, 98, 13734-13738.

58. Weng, Y. I., Huang, T. H. \& Yan, P. S. Methylated DNA immunoprecipitation and microarray-based analysis: detection of DNA methylation in breast cancer cell lines. Methods Mol. Biol. 90, 165-176 (2009).

59. Zhao, M. T., Whyte, J. J., Hopkins, G. M., Kirk, M. D. \& Prather, R. S. Methylated DNA immunoprecipitation and high-throughput sequencing (MeDIP-seq) using low amounts of genomic DNA. Cell. Reprogram. 16 (3), 175-184 (2014).

60. Su, J., Wang, Y., Xing, X., Liu, J. \& Zhang, Y. Genome-wide analysis of DNA methylation in bovine placentas. BMC genomics. 15 (1), 12 (2014).

61. Staunstrup, N. H. et al. Genome-wide DNA methylation profiling with MeDIP-seq using archived dried blood spots. Clin. Epigenetics. 8 (1), 1-10 (2016).

62. Memili, E. \& First, N. L. Zygotic and embryonic gene expression in cow: a review of timing and mechanisms of early gene expression as compared with other species. Zygote. 8 (1), 87-96 (2000).

63. Liu, W. et al. Identification of key factors conquering developmental arrest of somatic cell cloned embryos by combining embryo biopsy and single-cell sequencing. Cell Discov. 2 (1), 1-15 (2016).

64. Shyam, S. et al. Effect of Dickkopf-1 and colony stimulating factor-2 on the developmental competence, quality, gene expression and live birth rate of buffalo (Bubalus bubalis) embryos produced by hand-made cloning. Theriogenology. 157, 254-262 (2020).

65. Kim, H. R. et al. Abnormal Expression of TIMP-2, SOD, Vimentin and PAI Proteins in Cloned Bovine Placentae. Reprod. Domest. Anim. 44 (4), 714-717 (2009).

66. Gao, G. et al. Transcriptome-wide analysis of the SCNT bovine abnormal placenta during mid-to late gestation. Sci. Rep. 9 (1), 1-10 (2019).

\section{Figures}



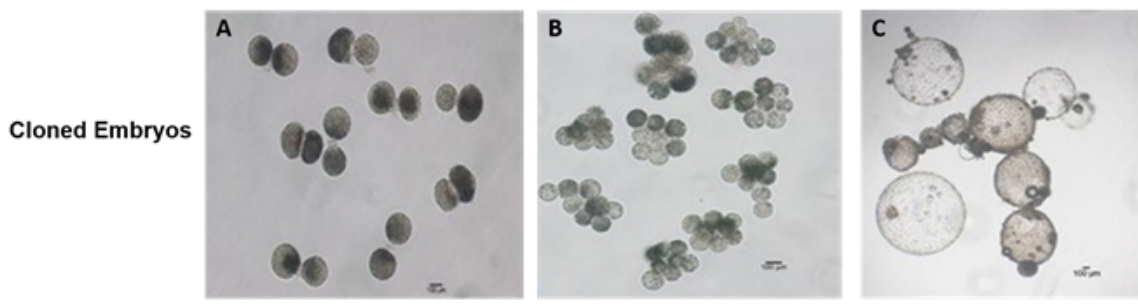

IVF Embryos
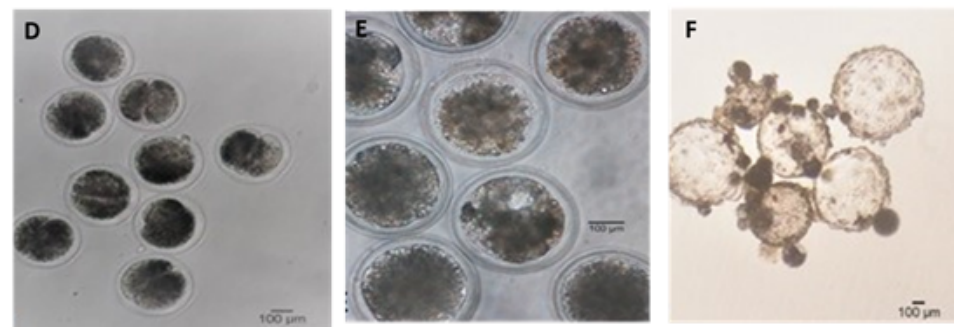

\section{Figure 1}

Cloned embryos at (A) 2-cell, (B) 8-cell and (C) blastocyst stage. (D), (E) and (F) are IVF embryos at corresponding stages.

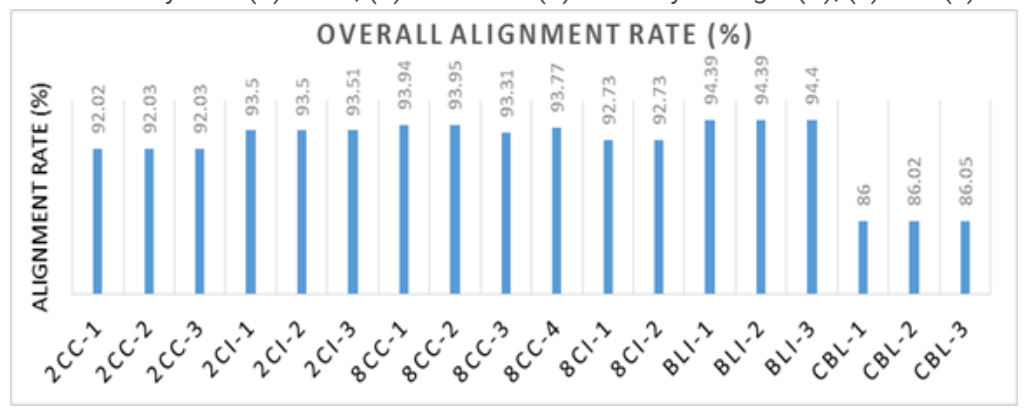

\section{Figure 2}

High-quality reads of Cloned 2-cell (2CC_1, 2CC_2 and 2CC_3), 8-cell (8CC_1, 8CC_2 and 8CC_3) and blastocyst stage (CBL_1, CBL_2 and CBL_3); IVF 2-cell (2Cl_1, 2Cl_2 and 2Cl_3), 8-cell (8Cl_1, 8Cl_2 and 8CI_3) and blastocyst stage (BLI_1, BLI_2 and BLI_3) embryos were aligned against Bos taurus reference genome, UMD 3.1.1. The percentage of total reads that got aligned was determined. For all the samples, 86 to $94.4 \%$ of the total reads got aligned against the reference genome. 


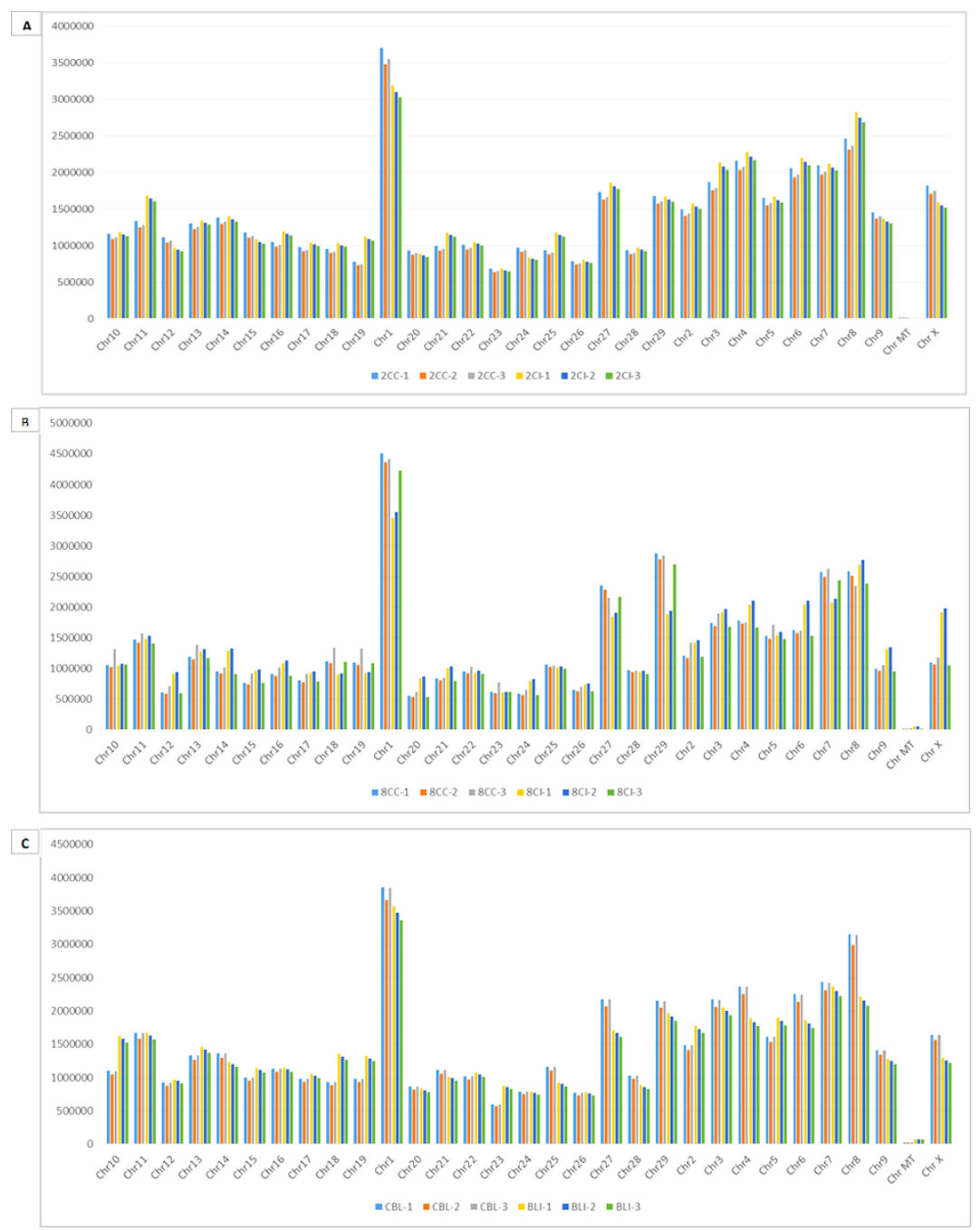

\section{Figure 3}

(A) Reads of 2-cell stage cloned (2CC-1, 2CC-2 and 2CC-3) and IVF (2Cl-1, 2Cl-2 and 2Cl-3) embryos were mapped to different chromosomes. (B) Reads of 8cell stage cloned (8CC-1, 8CC-2 and 8CC-3) and IVF (8Cl-1, 8Cl-2 and 8Cl-3) embryos were mapped to different chromosomes. (C) Reads of cloned (BL-1, BL-2 and BL-3) and IVF (BLI-1, BLI-2 and BLI-3) blastocyst-stage embryos were mapped to different chromosomes. A maximum number of reads were found to map on chromosome number 1 at all the developmental stages.

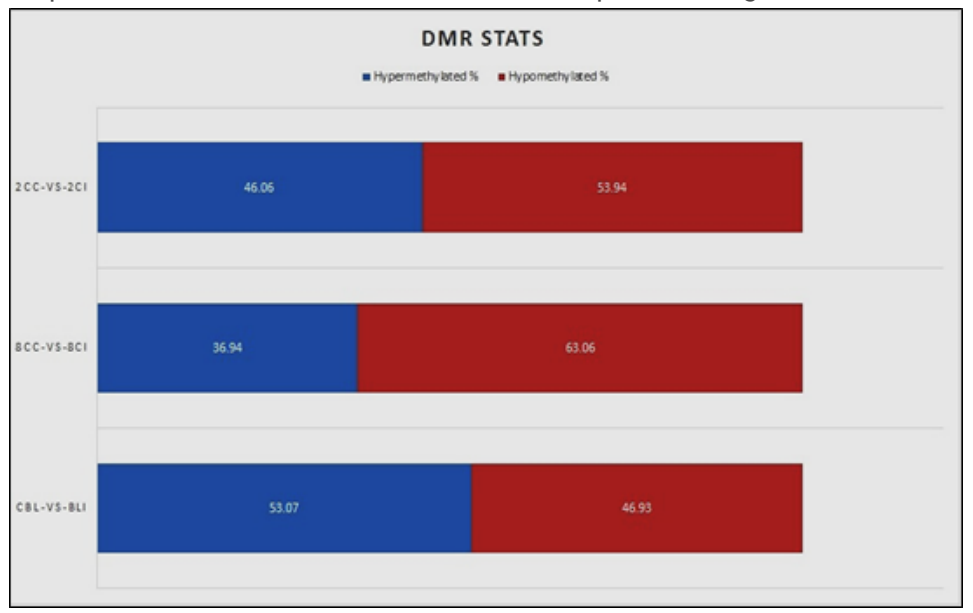

Figure 4

Overall distribution statistics of differentially methylated regions (DMRs). The X-axis represents comparison between cloned and IVF embryos at each developmental stage i.e., $2 \mathrm{CC}$ vs $2 \mathrm{Cl} ; 8 \mathrm{CC}$ vs $8 \mathrm{Cl}$ and $\mathrm{CBL}$ vs $\mathrm{BLI}$. The $\mathrm{Y}$-axis represents the number of DMRs. 

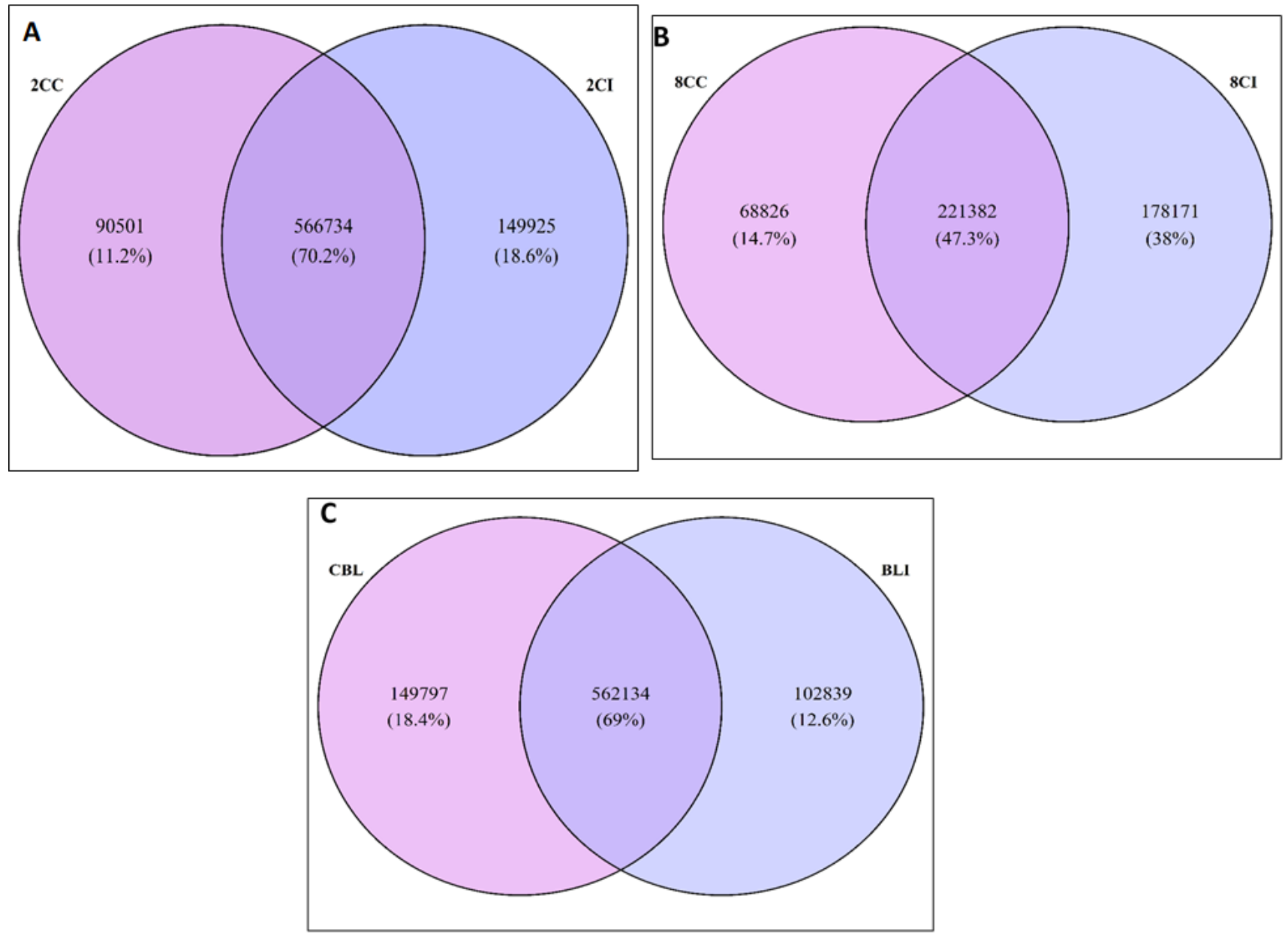

\section{Figure 5}

(A) Venn diagram depicting the DMRs hypermethylated commonly and uniquely in cloned and IVF 2-cell stage embryos $(P<0.05)$. (B) Venn diagrams depicting the DMRs, hypermethylated commonly and uniquely in cloned and IVF 8-cell stage embryos at $(P<0.05)$. (C) Venn diagram depicting the DMRs, hypermethylated commonly and uniquely in cloned and IVF blastocyst stage $(P<0.05)$. 

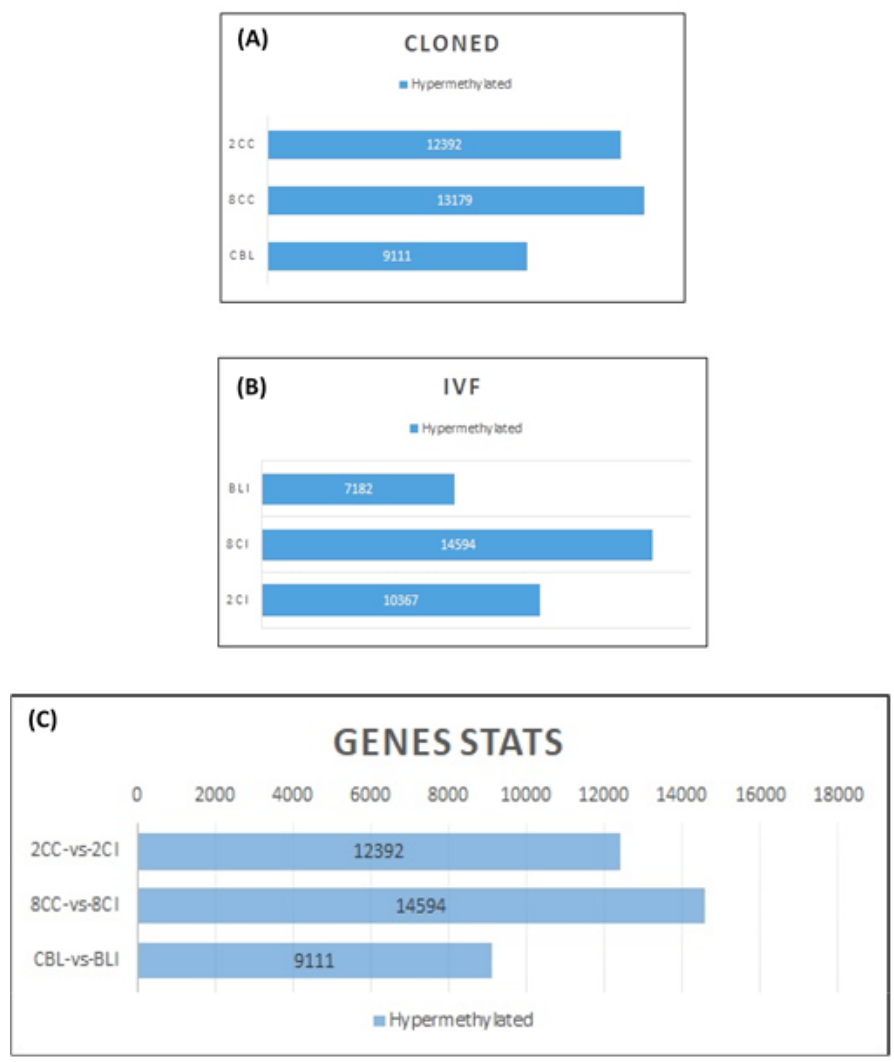

\section{Figure 6}

(A \& B) Overall distribution statistics of methylation at gene level. The Y-axis represents cloned (2CC, 8CC and CBL) and IVF (2Cl, 8Cl and BLI) embryos at different developmental stages. The X-axis represents the number of genes hypermethylated. (C) Overall distribution statistics of methylation at gene level. The $\mathrm{Y}$-axis represents comparison between cloned and IVF embryos at different developmental stages (2CC vs $2 \mathrm{Cl}, 8 \mathrm{CC}$ vs $8 \mathrm{Cl}$ and $\mathrm{CBL}$ vs $\mathrm{BLI}$ ). The $\mathrm{X}$-axis represents the number of genes hypermethylated. 


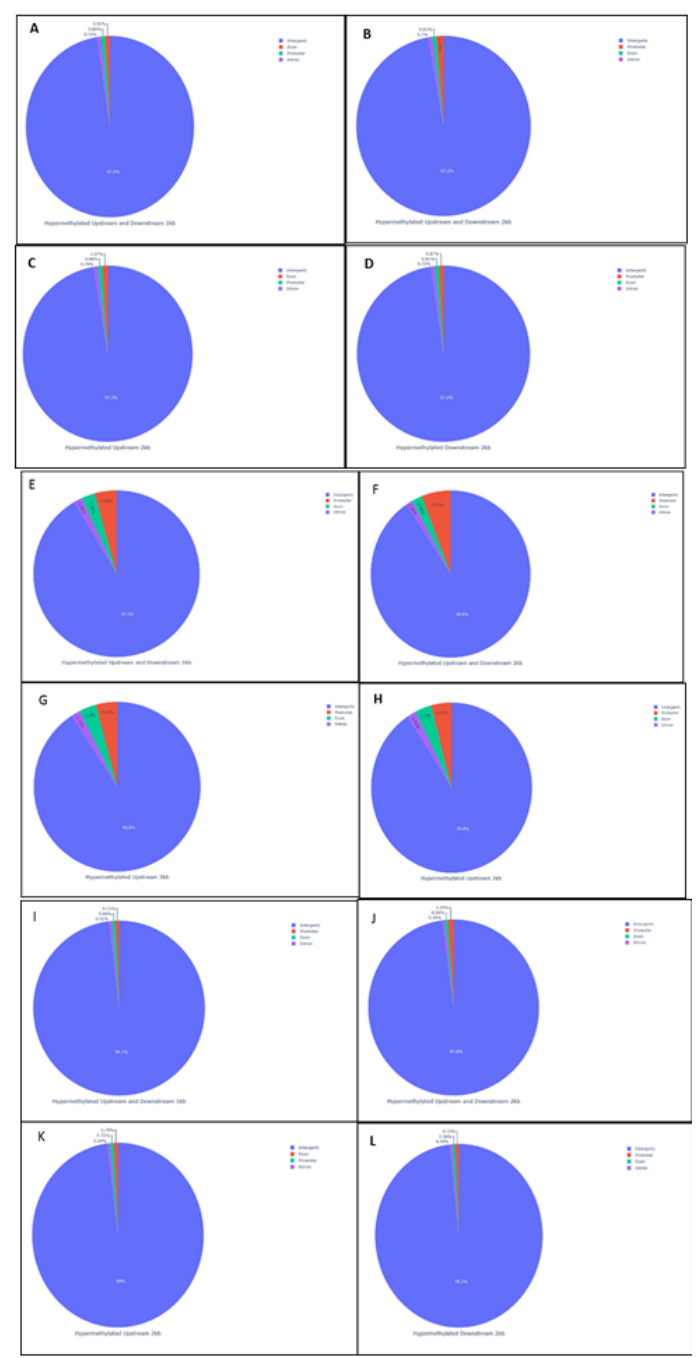

Figure 7

Venn diagram showing the overall genomic distribution of DMRs in cloned relative to IVF embryos. For 2-cell stage, (A and B) represent percentage of hypermethylated DMRs in upstream \& downstream $1 \mathrm{~Kb}$ and upstream \& downstream $2 \mathrm{~Kb}$ and $(\mathrm{C}$ and $\mathrm{D})$ represent percentage of hypermethylated DMRs in upstream $2 \mathrm{~Kb}$ and downstream respectively. For 8-cell stage, ( $\mathrm{E}$ and $\mathrm{F}$ ) represent percentage of hypermethylated DMRs in upstream \& downstream $1 \mathrm{~Kb}$ and upstream \& downstream $2 \mathrm{~Kb}$ and $(\mathrm{G}$ and $\mathrm{H})$ represent percentage of hypermethylated DMRs in upstream $2 \mathrm{~Kb}$ and downstream $2 \mathrm{~KB}$ respectively. For blastocyst stage, ( $\mathrm{l}$ and $\mathrm{J}$ ) represent percentage of hypermethylated DMRs in upstream \& downstream $1 \mathrm{~Kb}$ and upstream \& downstream $2 \mathrm{~Kb}$ and (K and $\mathrm{L}$ ) represent percentage of hypermethylated DMRs in upstream $2 \mathrm{~Kb}$ and downstream $2 \mathrm{~KB}$ respectively, of different genomic regions. 


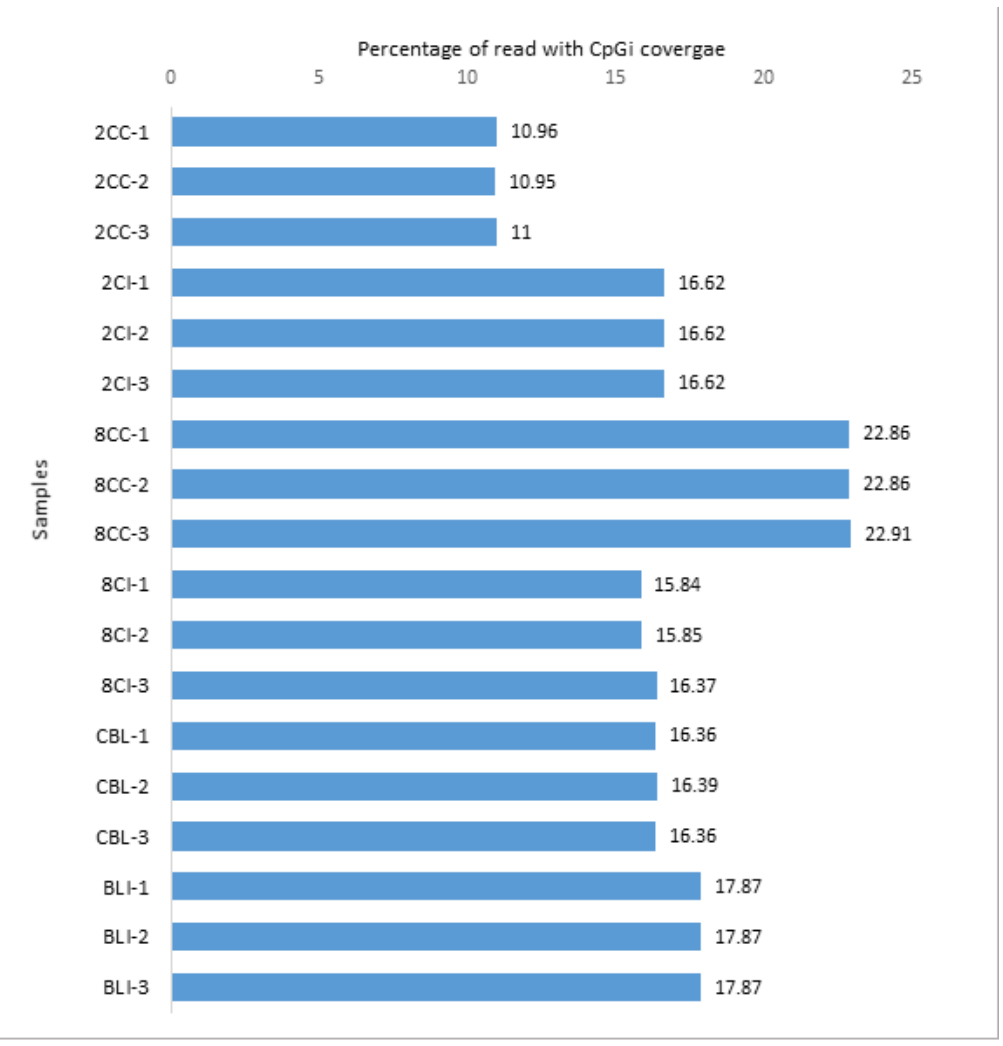

\section{Figure 8}

Percentage of reads mapped with $\mathrm{CpG}$ islands for each sample. The X-axis represents percentage (\%) range of mapped CGIs and the $\mathrm{Y}$-axis represents different stages of bovine cloned and IVF embryos i.e., biological replicates of cloned 2-cell stage embryos (2CC-1, 2CC3 and 2CC-3); IVF 2-cell stage embryos (2Cl-1, $2 \mathrm{Cl}-2$ and 2Cl-3); cloned 8-cell stage embryos (8CC-1, 8CC-2 and 8CC-3); IVF 8-cell stage embryos (8Cl-1, 8Cl-2 and 8Cl-3); cloned blastocyst stage embryos (CBL-1, CBL-2 and CBL-3) and IVF blastocyst stage embryos (BLI-1, BLI-2 and BLI-3).
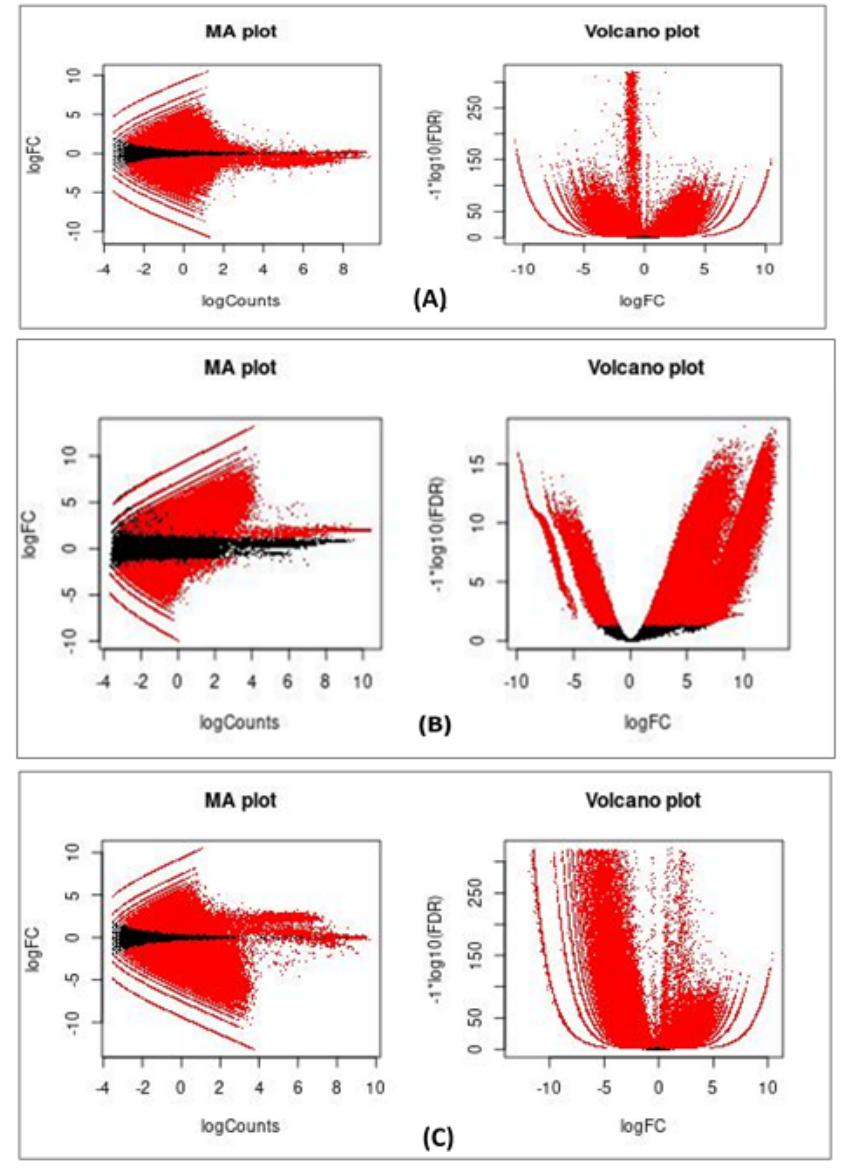


\section{Figure 9}

(A) MA plot depicting the global methylation pattern of hyper-and hypomethylated CpGs in cloned relative to IVF embryos at the 2-cell stage. The Y-axis represents the log fold ratio (M) and the X-axis, the mean average of normalized counts (A). Red dots represent differentially methylated regions (DMRs) having adjusted P-value above the threshold value whereas, black dots represent DMRs having P-value below the threshold.Volcano plot showing global methylation pattern of hyper- and hypomethylated CpGs in cloned realtive to IVF embryos at the 2-cell stage. Red dots indicate CpGs with significant differential methylation pattern whereas, black dots indicate $\mathrm{CpGs}$, the methylation pattern of which was non-significant in the two groups. The dots towards the left, right and top sides denote hypomethylated, hypermethylated and most significant differentially methylated CpGs, respectively. (B) MA plot and volcano plot depicting the global methylation pattern of hyper- and hypomethylated CpGs in cloned relative to IVF embryos at the 8-cell stage. (C) MA plot and volcano plot depicting the global methylation pattern of hyper- and hypomethylated CpGs in cloned relative to IVF embryos at the blastocyst stage.

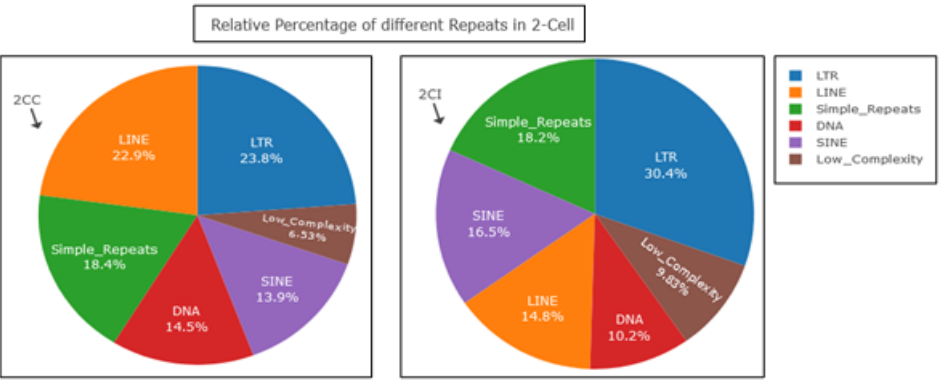

(A)

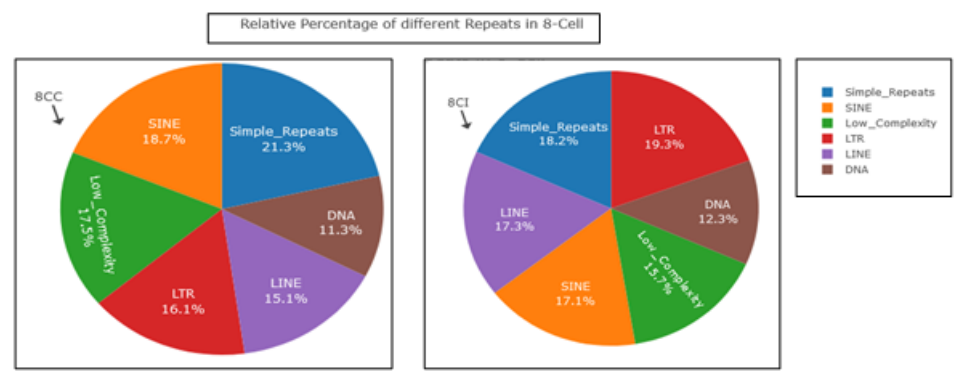

(B)

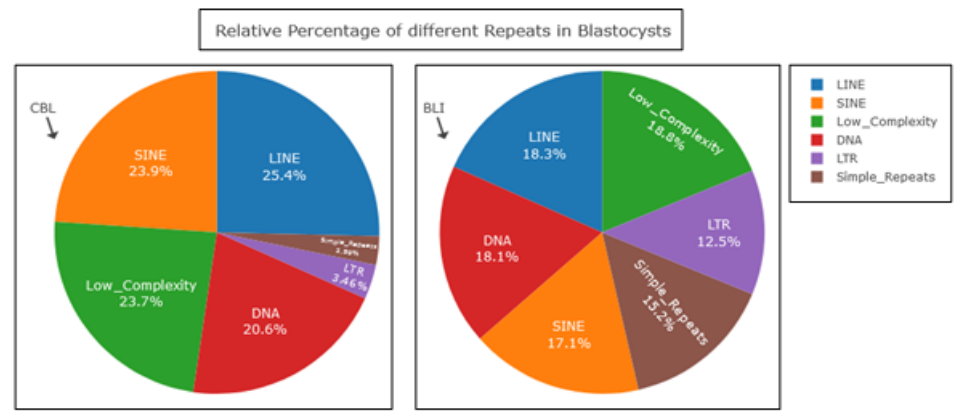

(C)

\section{Figure 10}

Pie-charts representing relative percentage of $\mathrm{CpG}$ islands found in a particular repetitive element at each developmental stage (A) 2-cell, (B) 8-cell and (C) blastocyst stage in cloned and IVF embryos relative to Bos taurus reference genome, UMD 3.1.1. 

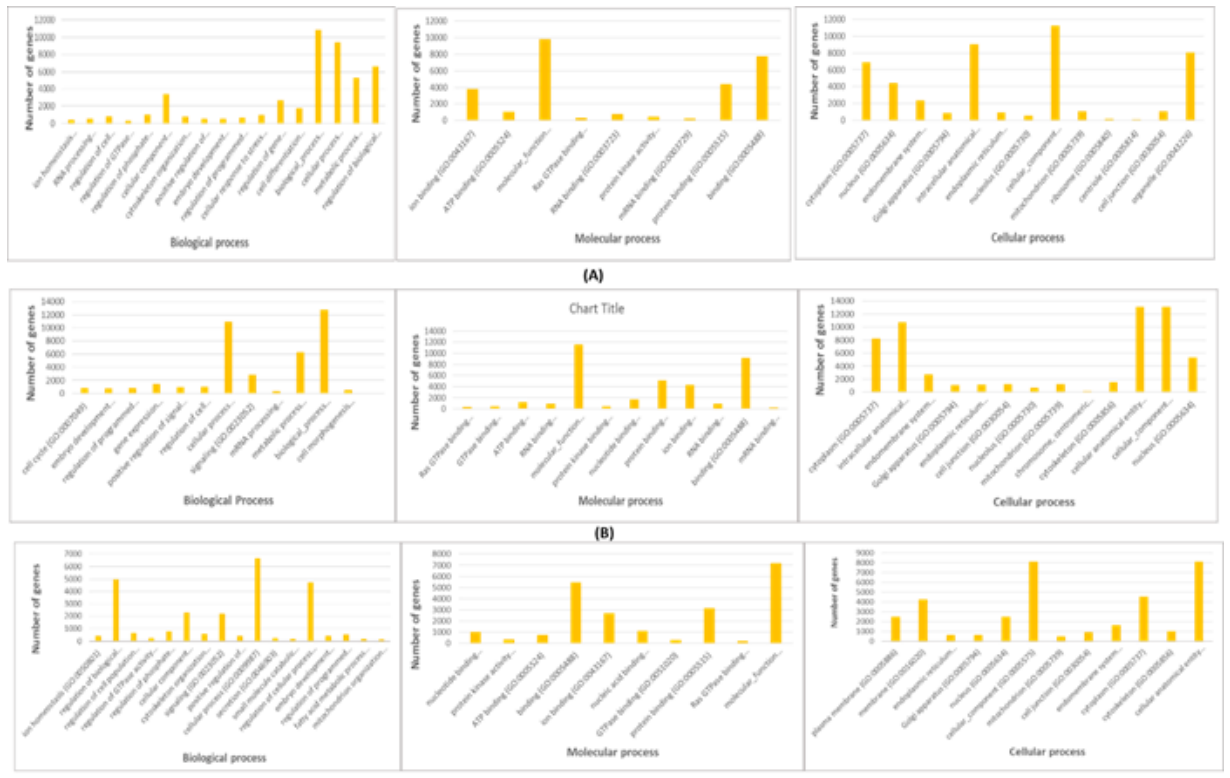

(C)

\section{Figure 11}

GO categories for Biological Process, Molecular process and Cellular process enriched across the hypermethylated genes in cloned relative to IVF A) 2-cell, B) 8-cell C) blastocyst stage embryos.
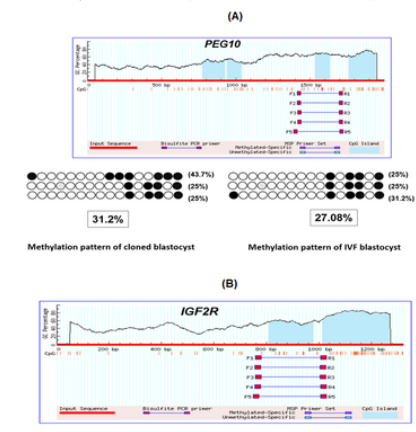

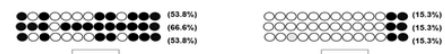
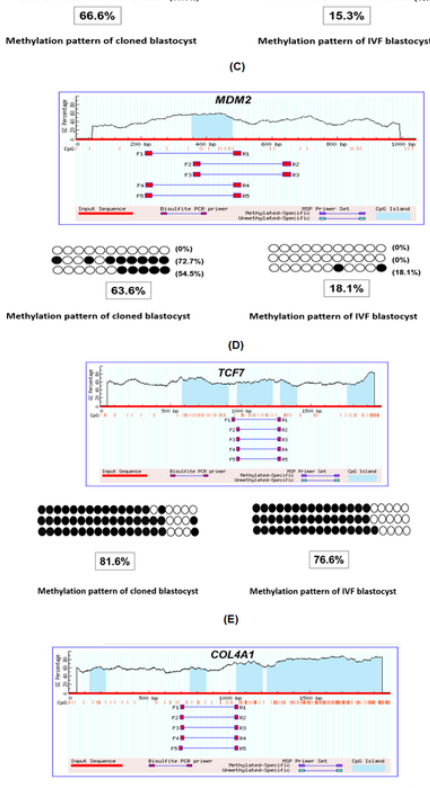

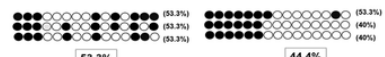

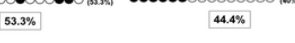

Figure 12 
Validation of MeDIP-Seq data by bisulfite sequencing. A total of 9 genes were selected randomly to validate MeDIP-Seq data by bisulfite PCR in blactocyststage cloned and IVF embryos. (A)DNA methylation status of upstream 2kb of IGF2R. CpG islands of upstream 2k of IGF2 were predicted by MethPrimer. F2$\mathrm{R} 2$ regions were chosen as the analyzed regions. DNA methylation status of IGF2 was analyzed by bisulfite sequencing. 13 circles in each horizontal line represent $13 \mathrm{CpGs}$ of IGF2. Unfilled (white) and filled (black) circles represent unmethylated and methylated CpGs, respectively. Horizontal lines of circles represent one separate replicate that was sequenced. Lollipop diagrams were generated by BIQ Analyzer software. For each sample, the methylation data were analyzed by computing the percentage of methylated $\mathrm{CpGs}$ of the total number of $\mathrm{CpGs}$. (B) DNA methylation status of upstream $2 \mathrm{~kb}$ of PEG10. CpG islands of upstream 2k of TCF7 were predicted by MethPrimer. F2-R2 regions were chosen as the analyzed regions. DNA methylation status of PEG10 was analyzed by bisulfite sequencing. 16 circles in each horizontal line represent 16 CpGs of PEG10. (C) DNA methylation status of upstream $2 \mathrm{~kb}$ of MDM2. CpG islands of upstream 2k of MDM2 were predicted by MethPrimer. F1-R1 regions were chosen as the analyzed regions. DNA methylation status of MDM2 was analyzed by bisulfite sequencing. 11 circles in each horizontal line represent $11 \mathrm{CpGs}$ of MDM2. (D) DNA methylation status of upstream $2 \mathrm{~kb}$ of TCF7. CpG islands of upstream 2k of TCF7 were predicted by MethPrimer. F1-R1 regions were chosen as the analyzed regions. DNA methylation status of TCF7 was analyzed by bisulfite sequencing. 20 circles in each horizontal line represent $20 \mathrm{CpGs}$ of TCF7. (E) DNA methylation status of upstream 2kb of COL4A1. CpG islands of upstream 2k of TCF7 were predicted by MethPrimer. F2-R2 regions were chosen as the analyzed regions. DNA methylation status of COL4A1 was analyzed by bisulfite sequencing. 15 circles in each horizontal line represent 15 CpGs of COL4A1.

\section{Supplementary Files}

This is a list of supplementary files associated with this preprint. Click to download.

- Supplementarysheets.xlsx 